\title{
Review Article \\ Interaction of Hydrogen Sulfide with Nitric Oxide in the Cardiovascular System
}

\author{
B. V. Nagpure and Jin-Song Bian \\ Department of Pharmacology, Yong Loo Lin School of Medicine, National University of Singapore, Singapore 117597 \\ Correspondence should be addressed to Jin-Song Bian; phcbjs@nus.edu.sg
}

Received 5 April 2015; Accepted 21 June 2015

Academic Editor: Alessandra Ricelli

Copyright (C) 2016 B. V. Nagpure and J.-S. Bian. This is an open access article distributed under the Creative Commons Attribution License, which permits unrestricted use, distribution, and reproduction in any medium, provided the original work is properly cited.

\begin{abstract}
Historically acknowledged as toxic gases, hydrogen sulfide $\left(\mathrm{H}_{2} \mathrm{~S}\right)$ and nitric oxide $(\mathrm{NO})$ are now recognized as the predominant members of a new family of signaling molecules, "gasotransmitters" in mammals. While $\mathrm{H}_{2} \mathrm{~S}$ is biosynthesized by three constitutively expressed enzymes (CBS, CSE, and 3-MST) from L-cysteine and homocysteine, NO is generated endogenously from $\mathrm{L}$-arginine by the action of various isoforms of NOS. Both gases have been transpired as the key and independent regulators of many physiological functions in mammalian cardiovascular, nervous, gastrointestinal, respiratory, and immune systems. The analogy between these two gasotransmitters is evident not only from their paracrine mode of signaling, but also from the identical and/or shared signaling transduction pathways. With the plethora of research in the pathophysiological role of gasotransmitters in various systems, the existence of interplay between these gases is being widely accepted. Chemical interaction between NO and $\mathrm{H}_{2} \mathrm{~S}$ may generate nitroxyl ( $\mathrm{HNO}$ ), which plays a specific effective role within the cardiovascular system. In this review article, we have attempted to provide current understanding of the individual and interactive roles of $\mathrm{H}_{2} \mathrm{~S}$ and NO signaling in mammalian cardiovascular system, focusing particularly on heart contractility, cardioprotection, vascular tone, angiogenesis, and oxidative stress.
\end{abstract}

\section{Introduction}

Endogenously produced hydrogen sulfide $\left(\mathrm{H}_{2} \mathrm{~S}\right)$ is responsible for inducing variety of physiologically favorable effects in different mammalian body systems. It is the youngest member of "gasotransmitter" family, along with nitric oxide (NO) and carbon monoxide (CO) [1]. Considered as toxic and potentially lethal gases for centuries, they are now recognized by many researchers as the important cytoprotective endogenous modulators of many physiological functions.

Although NO was identified as a gas in late eighteenth century, its role as a biological agent was confirmed only in 1980 [2]. Its generation from NO synthase (NOS) and its action as a vasodilator were discovered a few years later in 1987 [3]. NO is formed from guanidine nitrogen of L-arginine by the action of 3 isoforms of NOS, namely, endothelial (eNOS), inducible (iNOS), and neuronal (nNOS) [4]. The identification of $\mathrm{H}_{2} \mathrm{~S}$ as a toxic gas dates back even further than NO. The measurement of $\mathrm{H}_{2} \mathrm{~S}$ revealed its existence in the brain [5]. This suggests its probable physiological importance. The gradual discoveries of cystathionine $\beta$ synthase (CBS) and cystathionine $\gamma$-lyase (CSE) as critical enzymes producing $\mathrm{H}_{2} \mathrm{~S}$ [6] shed more light upon its signaling pathways and widespread physiological functions.

Being gaseous molecules and mediators, $\mathrm{H}_{2} \mathrm{~S}$ and $\mathrm{NO}$ exhibit many common traits like the unique ability of free diffusion through cell membranes without the need of specific membrane receptors. Their endogenous enzymatic production is deftly regulated at many levels. Furthermore, they are also involved in modulation of many physiological processes in cardiovascular system (CVS) and central nervous system (CNS) [1]. While the individual signaling mechanisms mediated by $\mathrm{H}_{2} \mathrm{~S}$ and $\mathrm{NO}$ in mammals are extensively studied, our understanding about the potential relationship between these two gasotransmitters is woefully incomplete. In 2009, first few definitive experimental evidences began to emerge voicing the probable "crosstalk" between $\mathrm{H}_{2} \mathrm{~S}$ and NO [7]. Since then, it is now an established fact that 


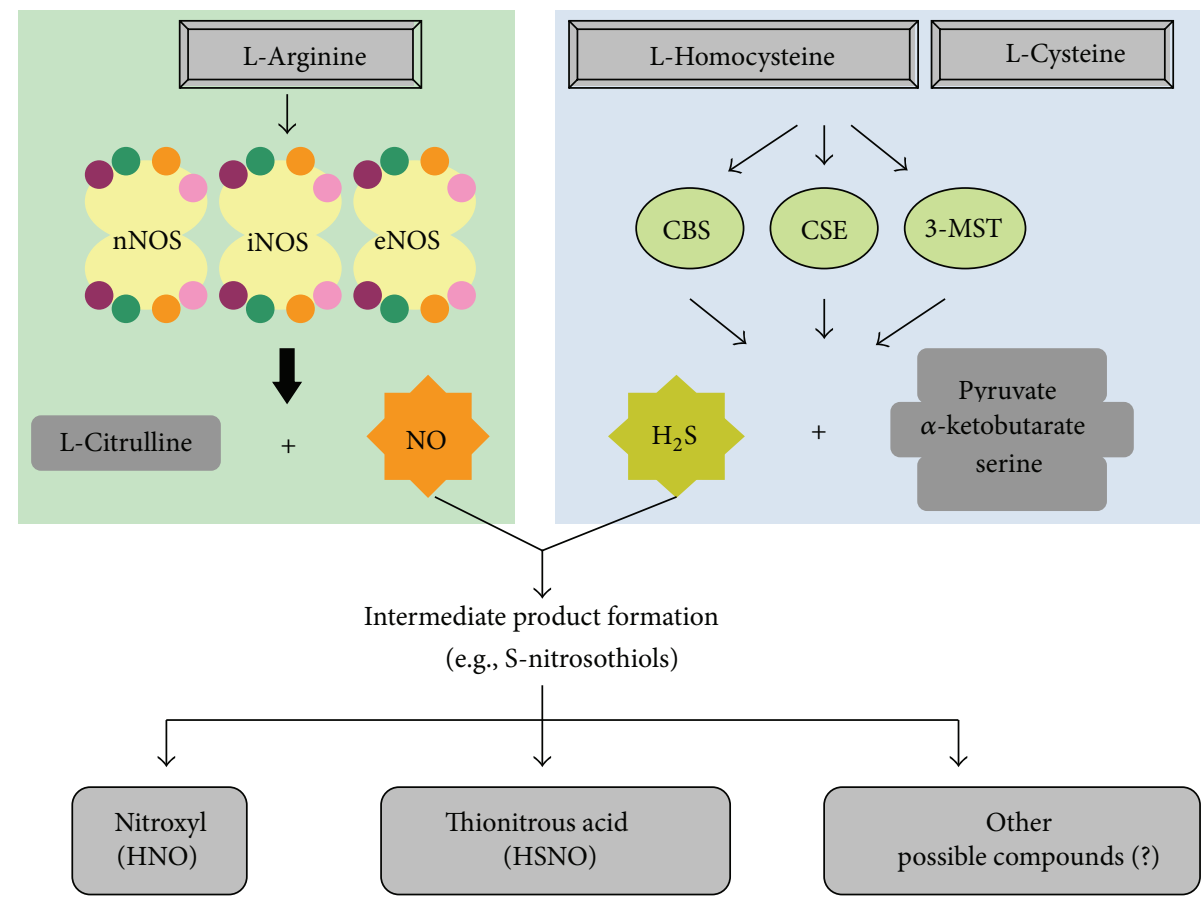

FIgURE 1: Biosynthesis of $\mathrm{NO}$ and $\mathrm{H}_{2} \mathrm{~S}$. NO is synthesized by three different isoforms of NOS, namely, nNOS, eNOS, and iNOS. These isoforms are almost identical in structure and functions. A functional NOS is made up of two identical monomers, each with four cosubstrates (NADPH, FAD, FMN, and $\mathrm{BH}_{4}$ ). L-Arginine is oxidized into L-citrulline along with the production of $\mathrm{NO}_{2} \mathrm{H}_{2} \mathrm{~S}$ is produced by the catalytic action of 3 different enzymes, CBS, CSE, and 3-MST. Each enzyme is expressed in organ-specific manner and catalyses the production of $\mathrm{H}_{2} \mathrm{~S}$ by oxidizing L-homocysteine and L-cysteine. Pyruvate, $\alpha$-ketobutyrate and serine are produced as bi-products. The interaction between these two gases can give rise to production of few intermediate products (e.g., S-nitrosothiols). As explained in this review article later, nitroxyl (HNO), thionitrous acid (HSNO), and other possible unknown compounds have been shown to induce some interesting effect in cardiovascular system.

these two gases influence each other at many levels from their biosynthesis to the various biological responses within cellular targets $[8,9]$. The therapeutic potential of these gases is immense and thus being explored via many preclinical and clinical studies [10]. In this review article, we will focus on physiological and cellular functions mediated by $\mathrm{H}_{2} \mathrm{~S}$ and NO in mammalian cardiovascular system. A prevailing understanding of the known and complex interplay between these gases and their signaling mechanisms would also be provided in the respective sections of the paper.

\section{Synthesis and Metabolism of $\mathrm{H}_{2} \mathrm{~S}$ in Mammalian Cells}

A major contribution in the endogenous production of $\mathrm{H}_{2} \mathrm{~S}$ is offered by two pyridoxal- $5^{\prime}$-phosphate- (PLP-) dependent enzymes, namely, CSE and CBS. They utilize L-cysteine or homocysteine as substrates [11]. Recently, however, a study reported that 3-mercaptopyruvate sulfurtransferase (3MST) acts together with cysteine aminotransferase (CAT) to generate $\mathrm{H}_{2} \mathrm{~S}$ in the brain (Figure 1). They also suggested that 3-MST and CAT are primarily involved in the neuronal production of $\mathrm{H}_{2} \mathrm{~S}$ [12]. While CBS and CSE are mainly cytosolic, 3-MST is preferably expressed in mitochondria [13]. Furthermore, their distribution is highly tissue specific. CBS is primarily detected in neurons and astrocytes of
CNS [14], whereas CSE is located in the CVS, especially the myocardial cells [15] and vascular smooth muscle cells [16]. The localization of CSE in endothelial cells (EC) is a bit controversial. A few research groups have detected its expression in the ECs $[17,18]$ while others have not reported as such $[19,20]$.

$\mathrm{H}_{2} \mathrm{~S}$ production by CBS involves the condensation reaction between homocysteine with L-cysteine to produce cystathionine and $\mathrm{H}_{2} \mathrm{~S}$ [21]. CSE catalyzes the conversion reaction of $\mathrm{L}$-cysteine into thiocysteine and pyruvate. The thiocysteine thus generated is lysed to form cysteine and $\mathrm{H}_{2} \mathrm{~S}$ [22]. CAT, on the other hand, catalyzes the synthesis of 3-mercaptopyruvate from L-cysteine and $\alpha$-ketoglutarate. 3-MST then desulfurates 3-mercaptopyruvate to generate thiosulfate. Later, $\mathrm{H}_{2} \mathrm{~S}$ is generated by reduction of thiosulfate [23]. Recently, Shibuya et al. identified a novel pathway of $\mathrm{H}_{2} \mathrm{~S}$ production specifically in kidney and the cerebellum region of the brain. $\mathrm{H}_{2} \mathrm{~S}$ can be generated from $\mathrm{D}$-cysteine by activation of 3-MST and D-amino acid oxidase [24]. The intracellular storage forms of $\mathrm{H}_{2} \mathrm{~S}$ have also been identified. Acid-labile sulfur is mainly located in the iron-sulfur cluster of mitochondria. Measured in the form of sulfide, acid-labile sulfur has been detected in brains of rats, bovines, and humans. It releases $\mathrm{H}_{2} \mathrm{~S}$ only in acidic microenvironment $(\mathrm{pH}=5.4)$ [19]. Due to the highly unstable nature of iron-sulfur clusters, $\mathrm{H}_{2} \mathrm{~S}$ is readily released when needed [20]. Bound sulfane sulfur, 
which is presented in cytosolic region, contains divalent sulfur bond (e.g., persulfide form). It releases $\mathrm{H}_{2} \mathrm{~S}$ under basic conditions ( $\mathrm{pH}$ 8.4) [20]. It is speculated that $\mathrm{H}_{2} \mathrm{~S}$ produced by 3-MST/CAT enzymatic pathway is stored in the bound sulfane sulfur form as lesser amount of bound sulfane sulfur has been detected in cells without 3-MST/CAT [15].

Under the physiological conditions, $\mathrm{H}_{2} \mathrm{~S}$ is quickly eliminated by various routes. Mitochondrial oxidation of deprotonated $\mathrm{HS}^{-}$results into thiosulphate, which is further converted into sulfite and eventually sulfate. Sulfate production is the primary fate of $\mathrm{H}_{2} \mathrm{~S}$ metabolism [25]. $\mathrm{H}_{2} \mathrm{~S}$ also undergoes cytosolic methylation by thiol S-methyltransferase to produce dimethylsulfide and methanethiol. $\mathrm{H}_{2} \mathrm{~S}$ has high affinity towards hemoglobin. Thus, $\mathrm{H}_{2} \mathrm{~S}$ binds to hemoglobin producing sulfhemoglobin [19].

\section{Synthesis and Metabolism of NO in Mammalian Cells}

Three different isoforms of the enzyme NOS produce NO in mammals. They are commonly known as neuronal nNOS (NOS I), inducible iNOS (NOS II), and endothelial eNOS (NOS III). Although genetically distinct, all three isoforms form NO from L-arginine with the help of two cosubstrates, namely, molecular $\mathrm{O}_{2}$ and nicotinamide-adeninedinucleotide phosphate (NADPH). The biosynthesis also requires various cofactors like flavin mononucleotide (FMN), flavin adenine dinucleotide (FAD), and tetrahydrobiopterin $\left(\mathrm{BH}_{4}\right)$ [4]. In a typical biosynthesis reaction, catalytically active NOS transfers electrons from NADPH to the heme, via FAD and FMS [26]. Calmodulin is bound to the reductase domains of monomers and it helps in facilitating the transfer of electrons [27]. These transferred electrons facilitate binding of molecular $\mathrm{O}_{2}$ to the ferrous form by reducing iron in the heme. The ferrous form is then combined to L-arginine to synthesize L-citrulline and NO [27, 28] (Figure 1). NO, thus generated, activates number of downstream secondary signaling pathways like soluble guanylyl cyclase activation which results into cGMP formation [29].

Besides CNS, nNOS is also identified in autonomic nerves of smooth muscles in blood vessels, gastrointestinal tract, respiratory tract, and genitourinary tract [30]. The expression of iNOS is identified in many immunological cell types such as macrophages [31] and neutrophils [32]. The third form, eNOS, is mainly expressed in endothelial cells but also present in other cell types such as cardiomyocytes, hepatocytes, intestinal cells, platelets, neurons, and astrocytes [33].

nNOS is primarily activated by glutamate acting on NMDA receptors. The enzyme activity is regulated by glutamate-induced rise in intracellular calcium $\left(\left[\mathrm{Ca}^{2+}\right]_{\mathrm{i}}\right)$ level and its interaction with calmodulin. Unlike nNOS, iNOS is neither affected by $\left[\mathrm{Ca}^{2+}\right]_{\mathrm{i}}$ levels nor dependent on the presence of cosubstrate NADPH and cofactor $\mathrm{BH}_{4}$ [34]. Its activity is stimulated by exposure to pathological insults, especially bacterial endotoxins and proinflammatory cytokines such as TNF- $\alpha$ and interleukins. The activation of eNOS is triggered by increased $\left[\mathrm{Ca}^{2+}\right]_{\mathrm{i}}$, which in turn is elevated by phosphoinositide secondary signaling pathway. Similar to
nNOS, eNOS activity is $\mathrm{Ca}^{2+}$ dependent and is regulated by calmodulin [30].

The nitrite $\left(\mathrm{NO}_{2}{ }^{-}\right)$and nitrate $\left(\mathrm{NO}_{3}{ }^{-}\right)$, collectively known as $\mathrm{NO}_{x}$, are the end products of endogenous $\mathrm{NO}$ metabolism in the mammalian cells [35]. They are also recycled physiologically to generate $\mathrm{NO}$ and other nitrogen oxides [36]. Recently, they have been acknowledged as "storage pools" of NO in mammalian tissues, complementing the NOS-dependent pathway of NO biosynthesis [35]. In another proposed mechanism of NO storage, reduced glutathione (GSH) is nitrosylised to generate S-nitroso-L-glutathione (GSNO) [37]. NO stored in the form of GSNO can be released by the action of many enzymes such as GSH peroxidase [38] and thioredoxin reductase [39].

Physiologically, endogenously generated NO is rapidly metabolized. It diffuses through lumen of blood vessels and intracellular compartments to react with hemoglobin. This elimination pathway leading to the formation of nitrates is considered as the major mechanism of NO catabolism [40]. In another mechanism, NO is oxidized in blood forming nitrites which react with hemoglobin producing nitrates [37]. As discussed before in this paper, excessive production of NO can be detrimental to the cells. This excessive NO reacts with bicarbonate to produce nitrosoperoxycarbonate $\left(\mathrm{ONOOCO}_{2}{ }^{-}\right)$and thus scavenged from the body [41].

\section{Biochemistry of $\mathrm{NO}-\mathrm{H}_{2} \mathrm{~S}$ Interaction}

The biological and chemical reactivities of $\mathrm{H}_{2} \mathrm{~S}$ have been discussed thoroughly in some excellent review papers previously $[42,43]$. After dissolving in water, $\mathrm{H}_{2} \mathrm{~S}$ dissociates in $\mathrm{H}^{+}, \mathrm{HS}^{-}$, and $\mathrm{S}^{2-}$. The anionic form $\mathrm{HS}^{-}$contributes to the major share while $\mathrm{S}^{2-}$ exists in a very small amount at the physiological $\mathrm{pH}$ [44]. The $\mathrm{H}_{2} \mathrm{~S} / \mathrm{HS}^{-}$form is a strong reducing agent, which is capable of reducing many organic substrates including NO and its oxidized forms. $\mathrm{H}_{2} \mathrm{~S}$ can form chemical complexes with nitrate, nitrite, S-nitrosothiols, and peroxinitrates [45]. In a previous work, Whiteman et al. demonstrated that mixture of various $\mathrm{NO}$ donors and $\mathrm{NaHS}\left(\mathrm{H}_{2} \mathrm{~S}\right.$ donor) forms a novel species known as nitrosothiols [46]. The study revealed that the addition of $\mathrm{H}_{2} \mathrm{~S}$ to various $\mathrm{NO}$ donors not only inhibits the release of $\mathrm{NO}$, but also alters the expected NO-based biological function. Their mechanism of formation is elusive but the direct reaction between $\mathrm{H}_{2} \mathrm{~S}$ and $\mathrm{NO}$ can be ruled out as $\mathrm{H}_{2} \mathrm{~S} / \mathrm{HS}^{-}$exists in diamagnetic acid/base pair while $\mathrm{NO}$ exhibits paramagnetic nature at the physiological $\mathrm{pH}$. The aerobic conditions maintained during these experiments might be responsible for $\mathrm{NO}$ oxidation leading to the formation of nitrosating species.

$\mathrm{H}_{2} \mathrm{~S}$ can reduce oxidized $\mathrm{NO}$ forms leading to the formation of $\mathrm{HSNO}$ as an intermediate. Further reduction and direct displacement of $\mathrm{HSNO}$ by $\mathrm{H}_{2} \mathrm{~S}$ results in the formation of yet another intermediate product, nitroxyl (HNO) [47] (Figure 2). HNO produces chemical and physiological functions different from $\mathrm{NO}$ [48] and $\mathrm{H}_{2} \mathrm{~S}$ [9, 49]. HNO is highly redox-sensitive and therefore regulates protein functions through "redox switches" [50, 51]. HNO can react with thiol groups in the cysteine residues to form 


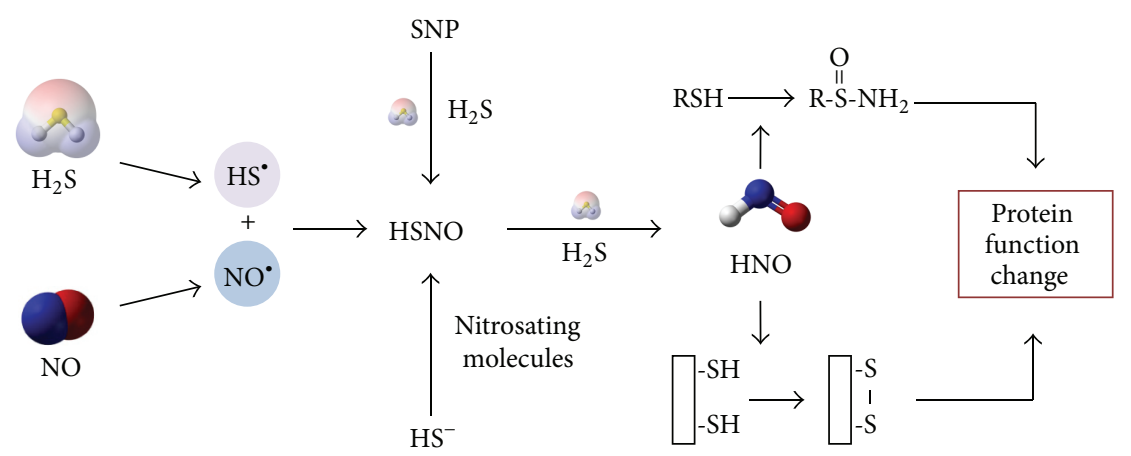

FIGURE 2: Simplifying depiction of chemical interaction between $\mathrm{H}_{2} \mathrm{~S}$ and NO. The radical of $\mathrm{H}_{2} \mathrm{~S}\left(\mathrm{HS}^{*}\right)$ reacts with that of $\mathrm{NO}^{\circ}\left(\mathrm{NO}^{\bullet}\right)$ to generate thionitrous acid (HSNO). In an alternate way, $\mathrm{HSNO}$ can be produced by hydrosulfide ion $\left(\mathrm{HS}^{-}\right.$), an anionic form of $\mathrm{H}_{2} \mathrm{~S}$, after its reaction with different nitrosating biomolecules. Sodium nitroprusside can also produce HSNO by reacting with $\mathrm{H}_{2} \mathrm{~S}$. In a further step of reaction, HSNO is acted upon by $\mathrm{H}_{2} \mathrm{~S}$ to produce HNO. HNO may modify the functions of proteins by converting their reactive thiols (thiolates) in cysteine residues to $\mathrm{N}$-hydroxysulfenamide (RSNHOH) or forming disulfide bond between two thiol groups in the near vicinity.

N-hydroxysulfenamide (RSNHOH) [52] or helps to form a reversible disulfide bond if there are two thiols residing in the near vicinity [53]. These modifications may induce conformational change and therefore the functions of the targeted proteins (Figure 2). The pharmacological effects of HNO donors have already brought attention of many research groups towards their potential therapeutic value against many cardiac ailments such as congestive cardiac failure. There are several types of $\mathrm{HNO}$ releasing compounds. The most commonly used one is Angeli's salt $\left(\mathrm{Na}_{2} \mathrm{~N}_{2} \mathrm{O}_{3}\right)$. Other donors include Piloty's acid $\left(\mathrm{PhSO}_{2} \mathrm{NHOH}\right)$ and its derivatives, isopropylamine-NO ${ }^{\bullet}$ (IPA/NO), and acyloxy nitroso compounds such as 1-nitrosocyclohexyl acetate (NCA, also known as the "blue compound") [54]. In the upcoming sections of this paper, we have discussed the effects of HNO on various aspects of cardiovascular physiology.

\section{5. $\mathrm{H}_{2} \mathrm{~S}$-NO Interaction in Cardiovascular System}

5.1. Role of $\mathrm{H}_{2} \mathrm{~S}-\mathrm{NO}$ Interaction in the Regulation of Heart Contractility. NO (both exogenous and endogenous) has concentration-dependent bimodal action on basal contractile state of cardiomyocytes. At low concentrations, NO exerts positive inotropic action [55]. The low NO levels activate adenylyl cyclase (AC) and downstream cAMP dependent signaling pathway [56]. Thus activated protein kinase A (PKA) phosphorylates voltage-dependent calcium channels and opens sarcoplasmic ryanodine receptors (Ry/R) [57]. The resultant increase in $\left[\mathrm{Ca}^{2+}\right]_{i}$ is mainly responsible for positive inotropic action. On the other hand, the negative inotropic effect by higher NO concentration is mediated chiefly through cGMP dependent pathway. The increased intracellular cGMP is further shown to downregulate myofilament calcium sensitivity increasing cardiac relaxation [58]. The cGMP regulator phosphodiesterase $5 \mathrm{~A}$ (PDE5A) is shown to modulate cardiac $\beta$-adrenergic stimulation in an eNOS dependent manner [59]. It is interesting to know that the mechanisms of action of NO depend upon the origin of endogenous $\mathrm{NO}$ as well. nNOS-derived $\mathrm{NO}$ has been demonstrated to upregulate cardiac contractility by direct protein S-nitrosylation of Ry/R receptors [60].

$\mathrm{NaHS}$ also produces a negative inotropic effect on cardiomyocytes by suppression of opening of $\mathrm{K}_{\mathrm{ATP}}$ channels [15, 61], blockade of L-type calcium channels [62], and suppression of cAMP/PKA pathway [63]. Accumulating evidences suggest that there is a cross-talk between $\mathrm{H}_{2} \mathrm{~S}$ and $\mathrm{NO}$ in the heart. $\mathrm{H}_{2} \mathrm{~S}$ may directly interact with $\mathrm{NO}$ during pathological situations like oxidative stress and alter cardiac functions. We were among the first groups to observe that $\mathrm{H}_{2} \mathrm{~S}$ reversed the negative inotropic and lusitropic effects of NO. Mixing NO donors (SNP, SIN-1, or SNAP) with NaHS produces an opposing effect on heart contractility as compared with either gas alone. To explain this phenomenon, we proposed the formation of new thiol sensitive molecule as they found that thiols abolished the effects of the mixture of $\mathrm{NO}$ and $\mathrm{H}_{2} \mathrm{~S}$ in their experimental setup $[9,49]$. It is also possible that $\mathrm{H}_{2} \mathrm{~S}$ reacts with either oxidized forms of $\mathrm{NO}$ (e.g., $\mathrm{NO}^{\circ}$ ) or nitrogen species $\left(\mathrm{ONOO}^{-}\right)$through $\mathrm{HS}^{-}$in the presence of cellular oxidants for example, molecular oxygen, ROS (e.g., $\mathrm{H}_{2} \mathrm{O}_{2}$ ), and oxidases. This process may generate new molecules like nitrosothiol, thionitrous acid (HSNO), or HNO [64]. Due to the strong reducing capability of $\mathrm{H}_{2} \mathrm{~S}[1,65,66]$, Yong et al. proposed that HNO could be one of the possible candidates [49]. This hypothesis was further confirmed by another group who studied the production of intracellular $\mathrm{HNO}$ in cells treated with nitrite $/ \mathrm{H}_{2} \mathrm{~S}$ reaction mixture with an HNO sensor (CuBOT1) [67]. The similar results were observed when sodium nitroprusside (SNP) was used as a NO donor $[68,69]$. The interaction of $\mathrm{H}_{2} \mathrm{~S}$ with $\mathrm{NO}$ and the resultant synthesis of thiol-sensitive compounds may also provide the justification behind the elusive bimodal effect of NO on cardiac contractility as mentioned in the beginning of this section.

Although the mechanisms for the positive inotropic effect of HNO are still not well understood, it is now believed that it is mediated by a $\beta$-adrenoceptor independent pathway [70, 71]. Inhibition of $c A M P / P K A$ and $C G M P / P K G$ had no significant impact on its inotropic effect [72]. In fact, the redox dependent mechanism is important for the positive inotropic 


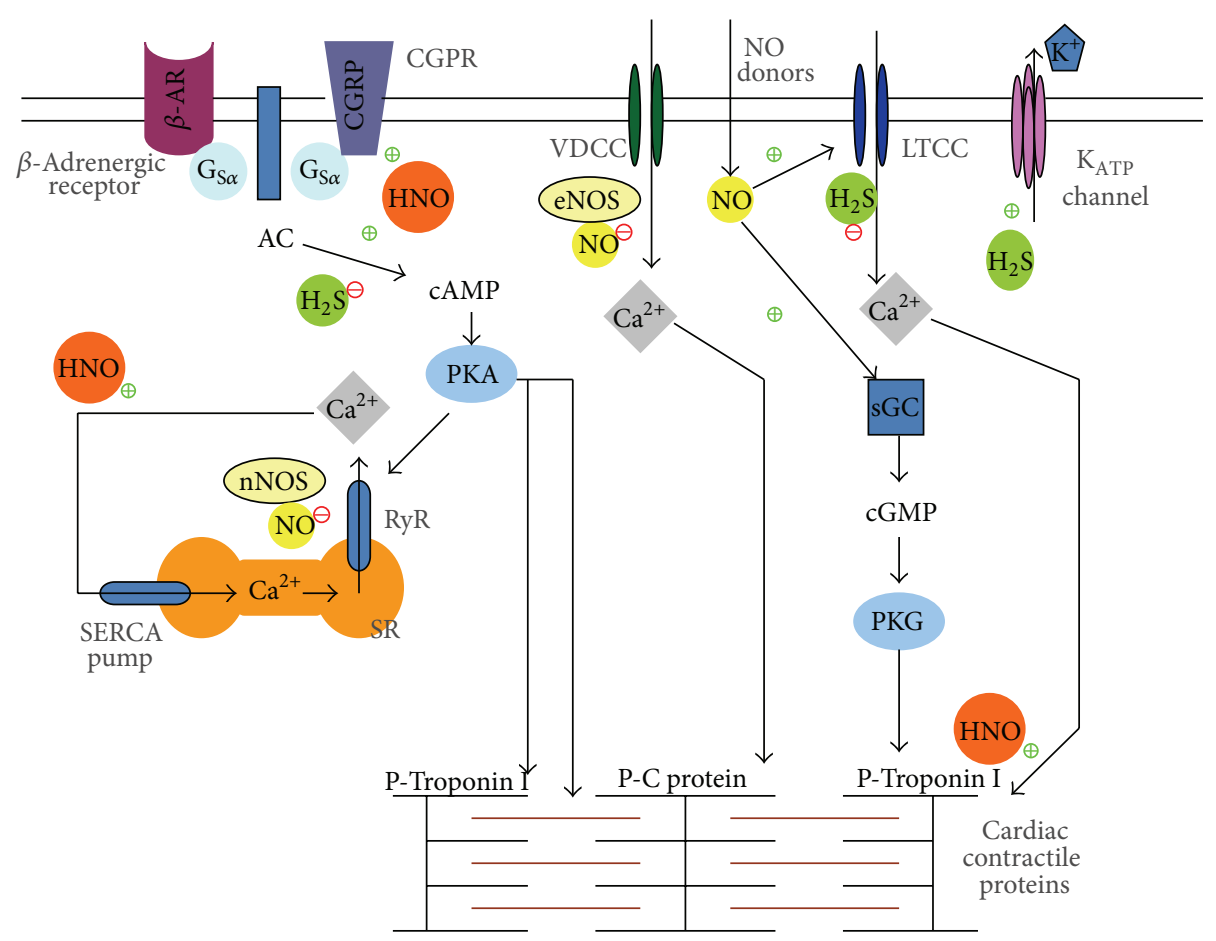

FIGURE 3: Effects of NO, $\mathrm{H}_{2} \mathrm{~S}$, and $\mathrm{HNO}$ on heart contractile function. The negative inotropic effect of NO is mediated mainly by cGMP-PKG pathway in CVS. Exogenous NO is believed to act via direct phosphorylation of LTCC and cardiac contractile proteins such as troponin 1. The effect of endogenous NO depends on the source. eNOS-generated NO acts via cGMP dependent pathway. nNOS-generated NO S-nitrosylates ryanodine receptors of sarcoplasmic reticulum. $\mathrm{H}_{2} \mathrm{~S}$ also exerts negative effect on cardiac contractility via (1) opening of $\mathrm{K}_{\text {ATP }}$ channels, (2) blockade of LTCC, and (3) inhibition of cAMP signaling pathway. Interestingly, the intermediate product, nitroxyl (HNO), produces positive inotropic effect. The possible underlying mechanisms of action include stimulation of calcitonin gene-related peptide signaling and enhancing cardiac sarcoplasmic reticulum $\mathrm{Ca}^{2+}$ cycling.

effect of HNO. HNO can enhance the myofilament calcium sensitivity through formation of an actin-TM heterodimer. With mass spectrometry (MS) and a modified biotin switch assay, Gao et al. even found out the four cysteine residues in myofilament modified by HNO [8]. HNO can also modulate the thiol groups in EC-coupling proteins and regulate the functions of these proteins. For instance, HNO modulates SERCA2a/phospholamban (PLN) interaction and therefore stimulates SR function [57]. More experiments revealed PLN is important in the HNO inotropy/lusitropy, as mutation of the three cysteine residues in PLN transmembrane domain abolished the effect of HNO [73]. Tocchetti et al. showed that the effect of $\mathrm{HNO}$ was from a direct interaction of $\mathrm{HNO}$ with the sarcoplasmic reticulum $\mathrm{Ca}^{2+}$ pump and the ryanodine receptor 2, leading to increased $\mathrm{Ca}^{2+}$ uptake and release from the sarcoplasmic reticulum [72].

In addition, Paolocci et al. reported that the positive inotropic signaling was mediated by calcitonin generelated peptide (CGRP), as treatment with the selective CGRP-receptor antagonist CGRP (8-37) prevented this effect [71]. However, this finding was later disproved as positive inotropic effects of CGRP were found to be mere sympathostimulatory in nature and downregulated by $\beta$-adrenoceptor blockers [74]. Nonetheless, the positive inotropic/lusitropic action of HNO render it to be an attractive addition to the current therapeutic armamentarium for treating patients with acutely decompensated congestive heart failure [75] (Figure 3).

5.2. Role of $\mathrm{H}_{2} \mathrm{~S}-\mathrm{NO}$ Interaction in the Cardioprotection. Myocardial ischemia occurs when cardiac myocytes are insufficiently provided with the oxygenated blood via coronary arteries, resulting in cardiovascular morbidity and mortality [76]. Ischemic injury is a complex process involving the action and interaction of many factors. NO is one of these factors to protect heart against ischemic injury. The studies conducted in eNOS deficient $\left(\mathrm{eNOS}^{-/-}\right)$mice [77] and eNOS overexpressing mice [78, 79] have concluded that eNOS-derived NO is a strong endogenous cardioprotective agent against cardiovascular pathologies including ischemiareperfusion (I/R) injury and congestive cardiac failure. The administration of $\mathrm{NO}$ donors also has similar protective effects in $I / R$ injury and other heart diseases in humans and other mammals [80-82]. The studies have revealed different possible underlying mechanisms including activation of sGC/cGMP/PKG signaling pathway [83], activation of subcellular $\mathrm{K}_{\mathrm{ATP}}$ channels $[84,85]$, and $\mathrm{Ca}^{2+}$ influx inhibition [86].

Similarly, the cardioprotective effects of $\mathrm{H}_{2} \mathrm{~S}$ also involve multiple mechanisms (Figure 3). This was described in detail in our previous review article [64]. Downregulation of endogenous $\mathrm{H}_{2} \mathrm{~S}$ production was found to increase 
myocardial infarct size, suggesting an important role of endogenous $\mathrm{H}_{2} \mathrm{~S}$ in maintaining the normal heart function [87]. In different animal models, $\mathrm{H}_{2} \mathrm{~S}$ was shown to protect heart against I/R injury via diverse mechanisms. Zhang et al. reported that $\mathrm{H}_{2} \mathrm{~S}$ stimulated opening of $\mathrm{K}_{\mathrm{ATP}}$ channels in cardiomyocytes [88]. The contribution of antiapoptotic signaling activation was demonstrated by the modulation of proteins expression including Beclin-1 [89], Bcl-2, Bax, caspase 3 [90], and HSP-90 [91]. $\mathrm{H}_{2} \mathrm{~S}$ is also known to preserve mitochondrial functions by modulating cellular respiration [92]. We and other groups revealed that the cardioprotective effect of $\mathrm{H}_{2} \mathrm{~S}$ preconditioning involves the activation of PKC and sarcolemmal $\mathrm{K}_{\mathrm{ATP}}$ channels, Akt, and eNOS pathways [93-96].

$\mathrm{H}_{2} \mathrm{~S}$ and NO may act in concert to protect the heart against ischemic injury. Inhibition of NO production with L-NAME, a nonselective inhibitor of NO synthases, significantly attenuated the cardioprotective effects of $\mathrm{H}_{2} \mathrm{~S}$ preconditioning [97]. Administration of NaHS alleviated isoproterenol-induced toxic cardiomyopathy through elevation of myocardial and serum $\mathrm{NO}$ levels [98]. $\mathrm{H}_{2} \mathrm{~S}$ may regulate NO production through modulation of eNOS and iNOS expression and activity. We showed previously that $\mathrm{H}_{2} \mathrm{~S}$ pretreatment activates eNOS pathway to confer protective effect against ischemic injury [93]. In an interesting study conducted in human umbilical vein endothelial cells (HUVECs-926), both eNOS phosphorylation and NO production were upregulated upon treatment with $\mathrm{NaHS}$ [99]. Moreover, malfunction of eNOS and reduced NO level were also found in CSE knockout mice. This contributes to the impaired heart function during I/R injury [100]. However, some conflicting effects were also reported. The data collected from rat and mouse aortic rings demonstrated that $\mathrm{H}_{2} \mathrm{~S}$ directly inhibited recombinant bovine eNOS activity [101]. In yet another study, both exogenous and endogenous $\mathrm{H}_{2} \mathrm{~S}$ inhibited eNOS transcription and activity [102]. Thus it is highly possible that the nature of effect of $\mathrm{H}_{2} \mathrm{~S}$ on eNOS is dependent on many factors including $\mathrm{H}_{2} \mathrm{~S}$ concentration and experimental setup.

Overexpression of iNOS and the subsequent excessive formation of NO may cause cytotoxic effects and exacerbate myocardial injury [103]. Inhibition of iNOS may produce beneficial effects in heart [104]. Apart from regulation of eNOS, $\mathrm{H}_{2} \mathrm{~S}$ also modulates iNOS expression. Hua et al. found that $\mathrm{H}_{2} \mathrm{~S}$ protected heart against CVB3-induced mice myocarditis through suppression of iNOS expression and the subsequent HO-1 pathway [105]. Taken together, NO is an important player in the cardioprotection induced by $\mathrm{H}_{2} \mathrm{~S}$, despite different mechanisms that may be involved in various pathological situations.

In contrast to the intensive investigation on the effect of $\mathrm{H}_{2} \mathrm{~S}$ on NO generation, little is known about the effect of NO on $\mathrm{H}_{2} \mathrm{~S}$ production. A previous study showed that exogenous application of an NO donor, sodium nitroprusside, and upregulated the expression of CBS and CSE, culminating in augmented $\mathrm{H}_{2} \mathrm{~S}$ production in rat tissues [106]. These data suggest that $\mathrm{H}_{2} \mathrm{~S}$ and $\mathrm{NO}$ may influence the production of each other by altering their generating abilities during ischemic situations.
However, the role of $\mathrm{HNO}$, the direct interaction product from these two gases, in ischemic reperfusion injury is still debated. Preconditioning with $\mathrm{HNO}$ also grants a protection similar to that afforded by classical ischemic preconditioning [107]. This protective effect was not from NO, as it cannot be achieved with equimolar amounts of the NO donors. The mechanisms underlying HNO-induced cardioprotection may involve mitochondrial $\mathrm{K}_{\mathrm{ATP}}$ channel $\left(\mathrm{mK}_{\mathrm{ATP}}\right)$ [108] (Figure 4). However, it is also worth noting that higher concentration perfusion of $\mathrm{HNO}$ may also produce detrimental effects during ischemic reperfusion caused by recruitment of neutrophils [109].

5.3. Role of $\mathrm{H}_{2} \mathrm{~S}-\mathrm{NO}$ Interaction in the Maintenance of Vascular Tone. The identification of $\mathrm{NO}$ as an endothelium derived relaxing factor [3] is a milestone in the field of gasotransmitters biology research. NO is now established as an important regulator of vascular tone. Physiologically, NO is a powerful vasodilator exerting its effect on various arteries, resistance vessels, and veins. The underlying signaling pathway is mainly cGMP dependent [110]. NO can also mediate vasodilation in a cGMP independent manner [111, 112]. SNitrosohemoglobin formed by S-nitrosylation of Cys 93 of the hemoglobin $\beta$ subunit has been demonstrated to moderate hypoxic vasodilation $[113,114]$.

$\mathrm{H}_{2} \mathrm{~S}$ has a biphasic effect on vascular tone in the cardiovascular system by mediating both vasorelaxation and vasoconstriction (Figure 5). Exogenously applied $\mathrm{H}_{2} \mathrm{~S}$ in higher concentrations (NaHS $>100 \mu \mathrm{M}$ ) relaxes vascular smooth muscles. It is suggested that the vasodilatory effect of endogenous $\mathrm{H}_{2} \mathrm{~S}$ is mainly responsible for the maintenance of basal tone in vasculature which in turn controls physiological blood pressure [115]. $\mathrm{H}_{2} \mathrm{~S}$ targets $\mathrm{K}_{\text {ATP }}$ channels to produce its vasodilatory effect $[16,115]$. Additional mechanisms such as involvement of the $\mathrm{Ca}^{2+}$ channels [116], $\mathrm{Cl}^{-} / \mathrm{HCO}_{3}{ }^{-}$exchanger [117], and metabolic inhibition [118] are required for the vasorelaxant effects of $\mathrm{H}_{2} \mathrm{~S}$. Interestingly, Ali et al. demonstrated the reversal of relaxant effect of endothelium/NO-dependent vasodilators (ACh and Histamine) by the treatment of $\mathrm{H}_{2} \mathrm{~S}$ in lower concentration (NaHS $<100 \mu \mathrm{M}$ ) [119]. This finding is in accordance with the previous results, where NaHS at concentration of $30 \mu \mathrm{M}$ induced a strong vasoconstrictive effect by itself. The mechanisms underlying the vasoconstrictive effects of low concentration of $\mathrm{H}_{2} \mathrm{~S}$ involve downregulation of endothelial NOS, decrease of intracellular cAMP level in smooth muscle cells, and production of ROS. This was discussed in details in our previous review [64].

Various experimental studies provided evidence for the interaction between $\mathrm{H}_{2} \mathrm{~S}$ and $\mathrm{NO}$ and the vasoregulatory role of this interaction. The first report of summation effect between $\mathrm{H}_{2} \mathrm{~S}$ and $\mathrm{NO}$ on vasorelaxation came from the findings of Hosoki et al. which demonstrated that $\mathrm{H}_{2} \mathrm{~S}$ can induce stronger relaxation effect in the presence of a NO donor [120]. Furthermore, pharmacological blockade of endogenous NO production or physical removal of the endothelium, attenuated $\mathrm{H}_{2} \mathrm{~S}$-induced relaxation [16]. These data suggest that the vasorelaxant effect of $\mathrm{H}_{2} \mathrm{~S}$ is mediated 


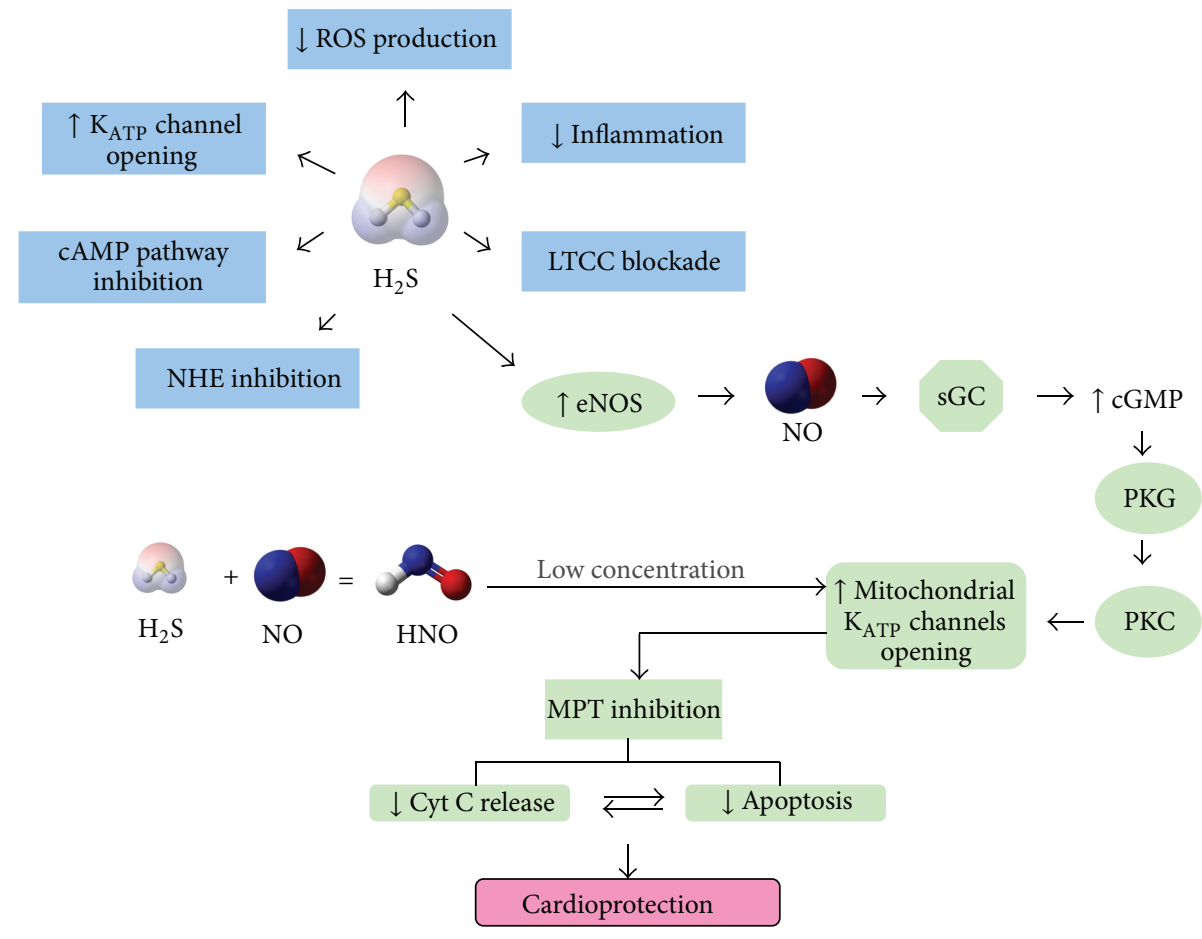

Figure 4: Cardioprotective effects of $\mathrm{NO}, \mathrm{H}_{2} \mathrm{~S}$, and $\mathrm{HNO}$. There are multiple underlying mechanisms for cardioprotective effect of $\mathrm{H}_{2} \mathrm{~S}$. It has been demonstrated to induce $\mathrm{K}_{\mathrm{ATP}}$ channel opening, abolish inflammation and oxidative stress by inhibiting ROS production, block LTCC and intracellular cAMP signaling pathway, and inhibit $\mathrm{Na}^{+} / \mathrm{H}^{+}$exchanger activity. Furthermore, NO also plays an important role in the cardioprotective effect of $\mathrm{H}_{2} \mathrm{~S}$. Endogenous NO generated from eNOS in endothelial cells initiates the sGC-cGMP-PKG cascade to increase openings of subcellular (mitochondrial) $\mathrm{K}_{\mathrm{ATP}}$ channels. The resultant inhibition of mitochondrial permeability transition (MPT) is responsible for decreased cytochrome $\mathrm{C}$ release and apoptosis in cardiomyocytes. HNO, depending on the concentration, can be either cardioprotective or cardiotoxic. At low concentration, just like $\mathrm{NO}, \mathrm{HNO}$ also stimulates $\mathrm{K}_{\mathrm{ATP}}$ channels opening in mitochondria.

by NO. The interplay between these two gases is different for the observed effect of vasoconstriction. Zhao and Wang found that $\mathrm{H}_{2} \mathrm{~S}$ inhibited SNP-induced vasorelaxation [116]. In line with this finding, Ali et al. found that a mixture of $\mathrm{NO}$ and $\mathrm{H}_{2} \mathrm{~S}$ reduced the extent of vasorelaxation compared to the relaxation with $\mathrm{NO}$ alone, implying the regulation of availability of $\mathrm{NO}$ by $\mathrm{H}_{2} \mathrm{~S}$. Interestingly, $\mathrm{H}_{2} \mathrm{~S}$ only induced vasoconstriction in endothelium-intact vessels but not in endothelium-denuded vessels.

The contractile effect of $\mathrm{H}_{2} \mathrm{~S}$ is therefore not a direct action on vascular smooth muscle cells but an indirect effect involving endothelial cells. Furthermore, they demonstrated that NaHS, in a dose-dependent manner, significantly downregulated vasorelaxant effect induced by chemically different NO donor molecules (e.g., SNP, SNAP). Similarly, NaHS reversed vasorelaxation induced by endogenous NO (from vascular endothelial cells) in a concentration dependent manner. This indicates that $\mathrm{H}_{2} \mathrm{~S}$ may induce vasoconstriction via direct quenching of NO. Interestingly, this group also hypothesized the formation of a new compound, nitrosothiol. Since copper sulfate, which converts nitrosothiol to nitrite and nitrates, prevented the contractile of aortic rings without influencing the vasorelaxant effect of $\mathrm{NaHS}$, the generation of nitrosothiols was proved. This nitrosothiol molecule might have contributed to the modulatory effect of $\mathrm{H}_{2} \mathrm{~S}$ on vascular tone [119]. Similarly, we found that $\mathrm{H}_{2} \mathrm{~S}$ may also stimulate anion exchanger- 2 activity which transports $\mathrm{HCO}_{3}{ }^{-}$in exchange of $\mathrm{O}_{2}{ }^{-}$to inactivate $\mathrm{NO}$ and thus inducing stronger vasoconstriction. In extracellular space, $\mathrm{O}_{2}{ }^{-}$reacts with $\mathrm{NO}$ to form $\mathrm{ONOO}^{-}$[121]. Since NO uptake by SMC is positively dependent on the level of intracellular $\mathrm{O}_{2}{ }^{-}$in SMC [122], the depletion of intracellular $\mathrm{O}_{2}{ }^{-}$may further inhibit $\mathrm{NO}$ uptake in SMC. These findings indicate that $\mathrm{H}_{2} \mathrm{~S}$ may induce vasoconstriction via inactivation of NO.

Recently, Berenyiova et al. found that of the interaction of sodium sulfide $\left(\mathrm{Na}_{2} \mathrm{~S}\right)$ and $\mathrm{S}$-nitrosoglutathione (GSNO) relaxed precontracted isolated rings of rat thoracic aorta and mesenteric artery with a much stronger potency than any of these two chemicals alone. They claimed that the formation of nitroxyl (HNO) is responsible for the pronounced relaxation induced by the sulfide/GSNO cross-talk [123].

HNO is produced endogenously in vascular tissue [124126]. It induces vasodilatory effect via multiple mechanisms. Previous reports showed that HNO may dilate vascular vessels as an endothelium-derived relaxing and hyperpolarizing factor $[127,128]$, via activation of a cGMP-dependent pathway [129] and via activation of TRPA1 receptor channels of trigeminal fibres inducing CGRP release [130]. Interestingly, not like NO, HNO does not develop tolerance in human blood vessels [129]. 


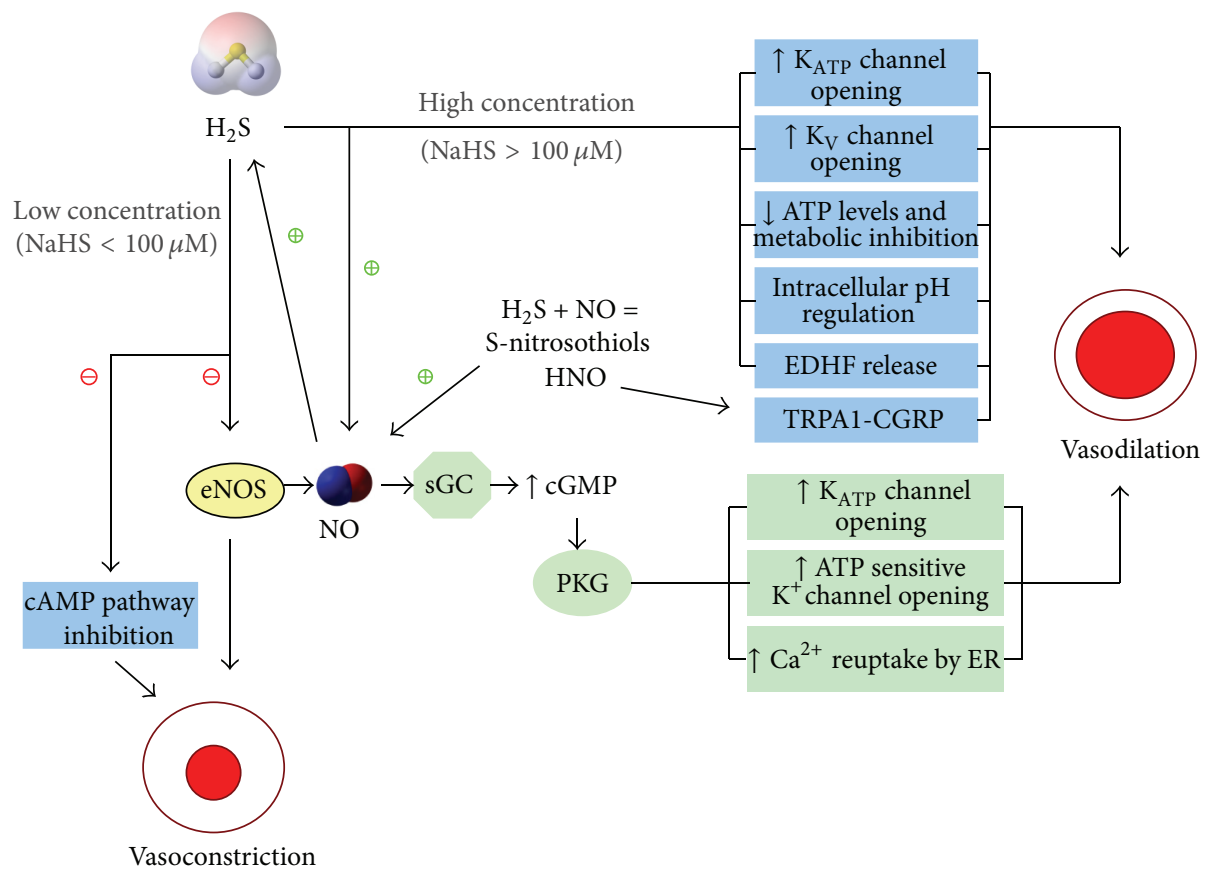

FIgURE 5: Regulatory effect of NO, $\mathrm{H}_{2} \mathrm{~S}$, and S-nitrosothiols on vascular tone. Depending upon the concentration, $\mathrm{H}_{2} \mathrm{~S}$ exerts biphasic response on vascular tone. At high concentration (NaHS $>100 \mu \mathrm{M}), \mathrm{H}_{2} \mathrm{~S}$ acts as a potent vasodilator by opening of $\mathrm{K}_{\mathrm{ATP}}$ and $\mathrm{K}_{\mathrm{V}}$ channels, downregulating ATP levels and cellular metabolism, regulating intracellular $\mathrm{pH}$ and release of endothelium-derived hyperpolarizing factor (EDHF). At low concentration (NaHS $<100 \mu \mathrm{M}$ ), however, $\mathrm{H}_{2} \mathrm{~S}$ acts as a vasoconstrictor by inhibiting eNOS-derived NO production and intracellular cAMP pathway. NO, by itself, is a strong vasodilator. Acting via cGMP-PKG pathway, it stimulates opening of $\mathrm{K}_{\text {ATP }}$ and ATPsensitive potassium channels. It also increases $\mathrm{Ca}^{2+}$ reuptake by endoplasmic reticulum and thus decreases intracellular $\mathrm{Ca}^{2+}$ levels resulting in less contraction. NO signaling is also stimulated by high concentration of $\mathrm{H}_{2} \mathrm{~S}$, contributing to its vasodilatory effect. S-nitrothiols, derived from interplay between $\mathrm{NO}$ and $\mathrm{H}_{2} \mathrm{~S}$, act as vasodilators mainly via $\mathrm{NO}$ signaling.

In addition to the direct interaction, $\mathrm{H}_{2} \mathrm{~S}$ and $\mathrm{NO}$ are also known to affect mutual production. NO can increase $\mathrm{H}_{2} \mathrm{~S}$ production in the normal vascular tissues. Incubation with $\mathrm{NO}$ donors increased $\mathrm{H}_{2} \mathrm{~S}$ production rate in the rat vascular tissues $[16,106]$. In pulmonary hypertension, higher $\mathrm{H}_{2} \mathrm{~S}$ production and upregulated CSE level were found in the presence of L-arginine [131]. On the other hand, $\mathrm{H}_{2} \mathrm{~S}$ may downregulate the aortic L-arginine/NO pathway [101, $102,121] . \mathrm{H}_{2} \mathrm{~S}$ inhibited recombinant eNOS activity and thus reduced NO synthesis in the endothelium [101]. In aortic tissues, Geng et al. also reported that $\mathrm{H}_{2} \mathrm{~S}$ suppressed NO production by inhibition of eNOS transcription, abundance. and activity [102]. Coletta et al. determined the cooperative effect of $\mathrm{H}_{2} \mathrm{~S}$ and NO by silencing CSE. It attenuated the NO donor induced cGMP accumulation and vasodilatorstimulated phosphoprotein (VASP) [132]. In a recent study, Eberhardt et al. showed that $\mathrm{HNO}$ formed from $\mathrm{H}_{2} \mathrm{~S}$ and $\mathrm{NO}$ activated transient receptor potential channel A1 (TRPA1). The sensory chemoreceptor channel TRPAl was activated via formation of amino-terminal disulphide bonds, which resulted in sustained $\mathrm{Ca}^{2+}$ influx. Consequently, calcitonin gene-related peptide (CGRP) was released inducing potent local and systemic vasodilation [133]. Thus it can be proposed that the $\mathrm{H}_{2} \mathrm{~S}$ and $\mathrm{NO}$ homeostasis is of the prime importance in maintaining vascular tone.
Short term application of exogenous $\mathrm{H}_{2} \mathrm{~S}$ reduced NO formation in cultured human umbilical vein endothelial cells through suppression of protein expression of eNOS but not those of nNOS and iNOS [102]. However, Huang et al. found that treatment with $\mathrm{NaHS}$ or $\mathrm{H}_{2} \mathrm{~S}$ releasing donor, ACS14, for $24 \mathrm{~h}$ attenuated the increase in iNOS expression caused by high glucose $(25 \mathrm{mM})$. This is similar to the inhibitory effect of $\mathrm{H}_{2} \mathrm{~S}$ on iNOS expression in heart [134]. These data suggest that $\mathrm{H}_{2} \mathrm{~S}$ may regulate iNOS expression in a time-dependent manner.

5.4. Role of $\mathrm{H}_{2} \mathrm{~S}-\mathrm{NO}$ Interaction in Angiogenesis. The formation of new blood vessels from preexisting vasculature through process of angiogenesis is the means by which cells can meet an elevated need of metabolites and in pathological conditions such as ischemia. Endothelial cells (ECs) play a pivotal role in the process by migrating towards and proliferating at the site of angiogenesis $[135,136]$.

Accumulating evidences suggest that gasotransmitters $\mathrm{NO}$ and $\mathrm{H}_{2} \mathrm{~S}$ are important factors to influence ECs and angiogenesis [8]. The relationship between $\mathrm{NO}$ and neovascularization is very well established [137] and found to involve cGMP transduction pathway [8]. Many angiogenic growth factors such as VEGF and basic fibroblast growth factor enhance eNOS expression and stimulate its activity to 
produce NO [138]. Cai et al. observed that NaHS stimulated the in vitro parameters of angiogenesis such as cell growth, migration, scratched wound healing, and tube-like structure formation in cultured $\mathrm{RF} / 6 \mathrm{~A}$ endothelial cells [139]. It was speculated that $\mathrm{H}_{2} \mathrm{~S}$ exerts its effects on ECs through $\mathrm{K}_{\text {ATP }}$ channels that in turn facilitate activation of MAPK pathways, leading to new blood vessel formation [140].

The signaling mechanisms of $\mathrm{H}_{2} \mathrm{~S}$ and $\mathrm{NO}$ are not mutually exclusive for angiogenesis. In an exhaustive study conducted by Coletta et al., PKG was concluded to be a converging point for the secondary signaling mechanisms of $\mathrm{H}_{2} \mathrm{~S}$ and NO [132]. In accordance with the previous results [141], this group found that the exogenous application of $\mathrm{H}_{2} \mathrm{~S}$ decreased cGMP degradation by inhibiting PDE5A. This effect on intracellular cGMP is aided and abetted by NO which activated sGC to stimulate the production of intracellular cGMP. As mentioned previously, $\mathrm{H}_{2} \mathrm{~S}$ stimulates Akt to induce its angiogenic effect. The stimulation of Akt in turn induces eNOS phosphorylation [142]. This particular response suggests that $\mathrm{H}_{2} \mathrm{~S}$ influences eNOS activity. Very few studies have addressed the role of HNO in angiogenesis. The first strong indication for the probable antiangiogenic role of HNO came from the studies conducted in animal models of neointimal hyperplasia. It was observed that inhibition of EC proliferation was partly responsible for inhibitory effects of IPA/NO on neointimal hyperplasia. It should be noted that either IPA/NO itself or products of IPA/NO decomposition could have caused these effects [143]. While working on in vitro and in vivo models of breast cancer, Norris et al. found that HNO treatment not only reduced blood vessel density but also downregulated angiogenesis. They observed lower levels of circulating serum VEGF and HIF- $1 \alpha$, both of which are potent proangiogenic factors [144].

\section{Role of $\mathrm{H}_{2} \mathrm{~S}$-NO Interaction in Oxidative Stress in CVS}

Obesity, hypertension, and aging are few distinct causative factor for cardiovascular diseases. They are accompanied by oxidative stress, which is the result of imbalance between ROS generating and ROS-scavenging systems [145-147]. It is now a well-established fact that ROS generation is ramped up in heart [134] and blood vessels [135] during cardiovascular pathologies. Oxidative stress is a result of excessive production of ROS like $\mathrm{O}_{2}^{-},{ }^{-} \mathrm{HO}, \mathrm{H}_{2} \mathrm{O}_{2}, \mathrm{NO}, \mathrm{ONOO}^{-}$, and $\mathrm{HClO}$, mainly as a byproducts of cellular aerobic metabolism. The action of certain enzymes like NADPH oxidase and NOS is of also crucial [137]. NADPH oxidase activity and mitochondrial electron transport chain are mainly responsible for ROS production in aging heart [138] and vasculature [139]. Increased ROS generation has many harmful consequences like stimulation of inflammatory response, apoptosis, and ER stress culminating into cellular damage [140].

$\mathrm{H}_{2} \mathrm{~S}$ is a well-known antioxidant [141] and it has been shown to protect vascular endothelial function under conditions of acute oxidative stress by directly scavenging $\mathrm{O}_{2}^{-}$ and downregulating vascular NADPH oxidase-derived $\mathrm{O}_{2}{ }^{-}$ production [142]. It has been reported that NO downregulates NADPH oxidase-dependent superoxide production in human endothelial cells by S-nitrosylation of p47phox subunit [148]. The chemical properties of HNO suggest that it can act as a potent antioxidant [149] as well. The low dissociation energy of $\mathrm{H}-\mathrm{NO}$ bond [150] makes HNO a strong reducing agent. Thus, $\mathrm{HNO}$ is speculated to quench reactive intermediate products produced during radical oxidation processes like lipid peroxidation [149]. It should also be noted that oxidation of HNO leads to production of NO, which itself is an antioxidant in nature [151]. Furthermore, HNO is demonstrated to have an effect on cGMP-dependent signaling pathway, which incidentally is a potent ROS-suppressing mechanism in the heart. The results of a study conducted by Lin et al. show that HNO suppresses NADPH oxidase by upregulating sGC and cGMP signaling in neonatal rat cardiomyocytes [152]. Interestingly, Miller et al. latest work revealed the sGC-cGMP-independent mechanism of action of HNO. They observed that HNO donors directly inhibited the activity of NADPH oxidase (vascular Nox2) in mouse cerebral arteries. They also proposed that HNO modifies reactive cysteine thiols in the subunits of vascular Nox2, thus reducing its activity [153]. HNO is also known to potentiate heme oxygenase-1 mRNA and protein expression leading to a significant elevation in its antioxidant and cytoprotective activities. It should also be noted that HNO, by downregulating $\mathrm{O}_{2}{ }^{-}$production, can increase the bioavailability of $\mathrm{NO}$ in oxidative stress. Impaired NO bioavailability is one of the most deleterious effect of aging on vascular well-being. Thus, $\mathrm{HNO}$ helps in maintaining proper functioning of CVS.

Both $\mathrm{H}_{2} \mathrm{~S}$ and $\mathrm{NO}$ have been shown to exhibit beneficial effect against oxidative stress in many biological systems including CVS. In last few years, the role of intermediate products released during the interaction between $\mathrm{H}_{2} \mathrm{~S}$ and NO has also been studied in oxidative stress pathology (Figure 6). Now it is generally agreed that HNO has significant potential to function as an antioxidant and hence further investigation is necessary to explore its prospective therapeutic benefits.

6.1. Perspectives. In recent few years, a few research groups have demonstrated the formation of novel intermediate species during the reaction between $\mathrm{H}_{2} \mathrm{~S}$ and $\mathrm{NO}$. In the initial work, the mixture of various $\mathrm{NO}$ donors and $\mathrm{H}_{2} \mathrm{~S}$ generated an intermediate formation with general properties similar to an S-nitrosothiol. Later, HSNO (thionitrous acid) was considered as the most likely S-nitrosothiol candidate [154]. Shortly after that discovery, a few of reports suggested $\mathrm{HNO}$ generation from the reaction between $\mathrm{NO}$ and $\mathrm{H}_{2} \mathrm{~S}$ donors $[49,75]$. The endogenous production of HNO is also speculated, and lots of efforts have been put in developing reliable $\mathrm{HNO}$ detection methods in order to understand endogenous HNO generation. Several approaches including electrochemical analysis [155], high-performance liquid chromatography [156], and mass spectrometry [157] have been used to detect HNO in various biological samples. However, these methods either lacked sensitivity or specificity towards endogenously generated HNO. Hence, novel HNO 


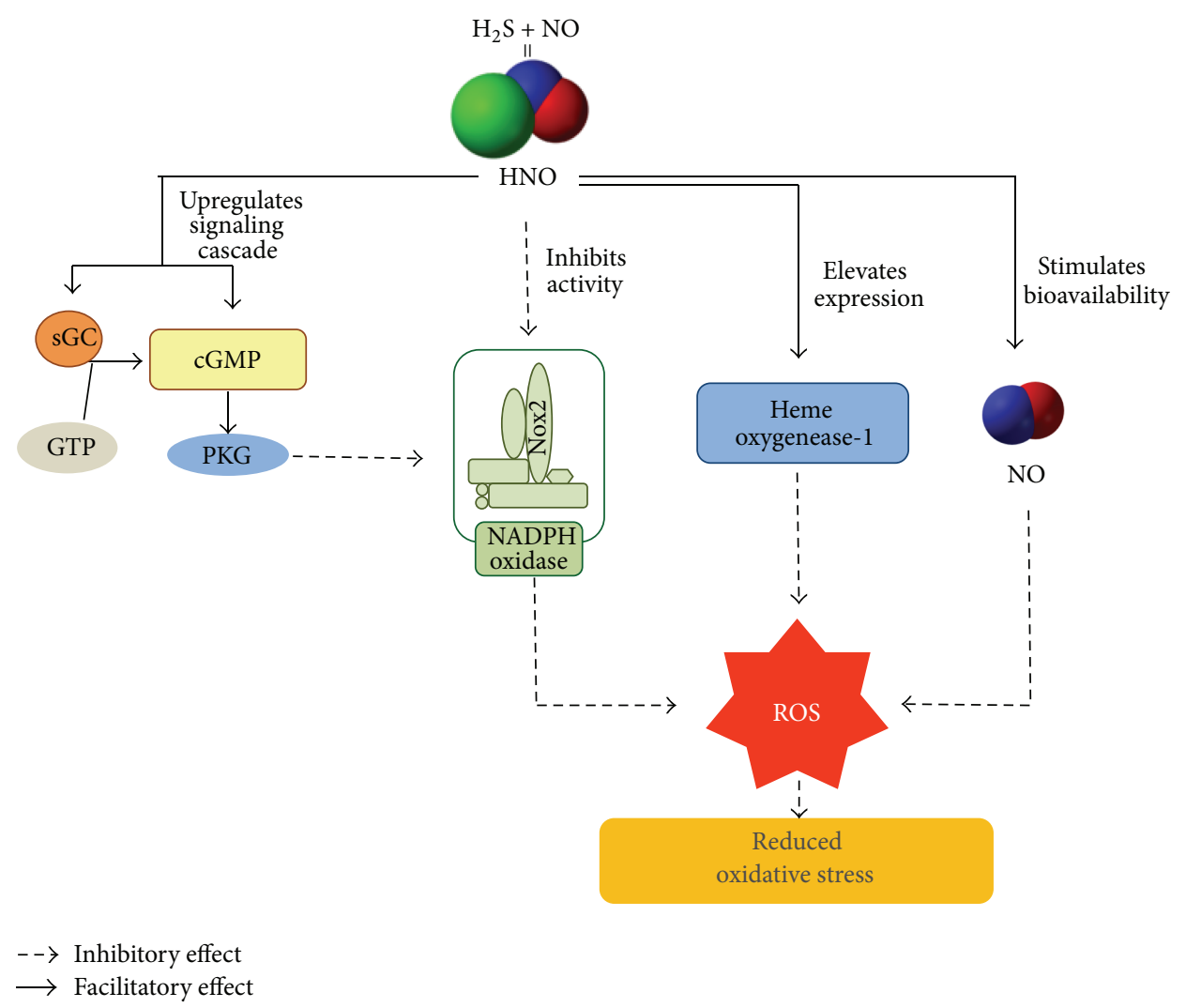

Figure 6: Role of $\mathrm{H}_{2} \mathrm{~S}-\mathrm{NO}$ interaction in oxidative stress in CVS. The primary target of action of HNO is NADPH oxidase, which is the main culprit enzyme for endogenous synthesis of ROS in aging CVS. HNO can inhibit its activity in both sGC-cGMP dependent and independent ways. HNO is also known to strengthen anti-inflammatory response by elevating heme oxygenase-1 expression. $\mathrm{HNO}$ increases the diminished bioavailability of NO in oxidative stress, resulting in proper functioning of heart and blood vessels.

detection approaches including $\mathrm{Cu}^{2+}$-medicated fluorescent probes and HNO-specific electrodes were adopted [155, 158]. Recently, a novel coumarin-based fluorescent probe, P-CM, was developed. It has been applied for selective quantitative detection of HNO in bovine serum samples [159]. Jing et al. successfully detected lysosomal HNO in cell system (RAW 264.7 macrophage cells) and in vivo using a newly synthesized a near-infrared fluorescent probe Lyso-JN [160].

It is speculated that $\mathrm{HNO}$ is produced endogenously in low concentration and perhaps insufficient to elicit any significant physiological effect [49]. The mechanisms proposed are still under investigation and include $\mathrm{NO}$ reduction [161], reaction of S-nitrosothiol with thiols [162], and reaction catalyzed by NOS. HNO is biochemically different from NO and $\mathrm{H}_{2} \mathrm{~S}$ and is known to show increased cardiac tissue contractility [163]. Furthermore, studies have implied that endogenous $\mathrm{HNO}$ production is elevated during pathological situations such as inflammation [7, 164]. Thus HNO and its derivatives are rapidly drawing attention as a potential pharmacological target in treatment of congestive cardiac failure [165] and acute heart failure [166].

However even with the favorable results, there are some concerns raised about the physiological relevance of these studies. For one thing, all these studies have utilized the supraphysiological concentrations of $\mathrm{NO}$ and $\mathrm{H}_{2} \mathrm{~S}$. Furthermore, the use of exogenously added NO donors, instead of stimulating endogenous source of $\mathrm{NO}$, are also debatable. For example, SNP does not release NO spontaneously and thus fails to mimic endogenous production and response of $\mathrm{NO}$ [167]. The known reactivity of SNP and $\mathrm{H}_{2} \mathrm{~S}$ further complicates the matter as it might generate products different from those generated in biological reaction between $\mathrm{H}_{2} \mathrm{~S}$ and NO $[47,49,154]$.

Although additional investigations are warranted to establish the exact mechanisms of action of $\mathrm{H}_{2} \mathrm{~S}$ and $\mathrm{NO}$, the importance and necessity of these two functional molecules in regulation of mammalian cardiovascular system are beyond debate. Our knowledge on these two gasotransmitters is expanding continuously and it is now evident that interaction between their molecular pathways is increasingly investigated as the future direction for the research in the area of gasotransmitters.

\section{Conflict of Interests}

The authors declare that there is no conflict of interests regarding the publication of this paper. 


\section{Acknowledgments}

This work was supported by NUHS B2B research grant (NUHSRO/2011/012/STB/B2B-08) and National Kidney Foundation (NKF, NKFRC/2009/01/10).

\section{References}

[1] R. Wang, "Two's company, three's a crowd: Can $\mathrm{H}_{2} \mathrm{~S}$ be the third endogenous gaseous transmitter?" The FASEB Journal, vol. 16, no. 13, pp. 1792-1798, 2002.

[2] R. F. Furchgott and J. V. Zawadzki, "The obligatory role of endothelial cells in the relaxation of arterial smooth muscle by acetylcholine," Nature, vol. 288, no. 5789, pp. 373-376, 1980.

[3] L. J. Ignarro, G. M. Buga, K. S. Wood, R. E. Byrns, and G. Chaudhuri, "Endothelium-derived relaxing factor produced and released from artery and vein is nitric oxide," Proceedings of the National Academy of Sciences of the United States of America, vol. 84, no. 24, pp. 9265-9269, 1987.

[4] S. Moncada, R. M. J. Palmer, and E. A. Higgs, "Nitric oxide: physiology, pathophysiology, and pharmacology," Pharmacological Reviews, vol. 43, no. 2, pp. 109-142, 1991.

[5] L. R. Goodwin, D. Francom, F. P. Dieken et al., "Determination of sulfide in brain tissue by gas dialysis/ion chromatography: postmortem studies and two case reports," Journal of Analytical Toxicology, vol. 13, no. 2, pp. 105-109, 1989.

[6] L. Li, P. Rose, and P. K. Moore, "Hydrogen sulfide and cell signaling," Annual Review of Pharmacology and Toxicology, vol. 51, no. 1, pp. 169-187, 2011.

[7] M. Whiteman and P. K. Moore, "Hydrogen sulfide and the vasculature: a novel vasculoprotective entity and regulator of nitric oxide bioavailability?" Journal of Cellular and Molecular Medicine, vol. 13, no. 3, pp. 488-507, 2009.

[8] W. D. Gao, C. I. Murray, Y. Tian et al., "Nitroxyl-mediated disulfide bond formation between cardiac myofilament cysteines enhances contractile function," Circulation Research, vol. 111, no. 8, pp. 1002-1011, 2012.

[9] Q.-C. Yong, J. L. Cheong, F. Hua et al., "Regulation of heart function by endogenous gaseous mediators-crosstalk between nitric oxide and hydrogen sulfide," Antioxidants and Redox Signaling, vol. 14, no. 11, pp. 2081-2091, 2011.

[10] C. Szabo, "Gaseotransmitters: new frontiers for translational science," Science Translational Medicine, vol. 2, no. 59, Article ID 59ps54, 2010.

[11] L.-F. Hu, M. Lu, P. T. Hon Wong, and J.-S. Bian, "Hydrogen sulfide: neurophysiology and neuropathology," Antioxidants and Redox Signaling, vol. 15, no. 2, pp. 405-419, 2011.

[12] N. Shibuya, M. Tanaka, M. Yoshida et al., "3-Mercaptopyruvate sulfurtransferase produces hydrogen sulfide and bound sulfane sulfur in the brain," Antioxidants \& Redox Signaling, vol. 11, no. 4, pp. 703-714, 2009.

[13] W. Guo, Z.-Y. Cheng, and Y.-Z. Zhu, "Hydrogen sulfide and translational medicine," Acta Pharmacologica Sinica, vol. 34, no. 10, pp. 1284-1291, 2013.

[14] K. Abe and H. Kimura, "The possible role of hydrogen sulfide as an endogenous neuromodulator," Journal of Neuroscience, vol. 16, no. 3, pp. 1066-1071, 1996.

[15] B. Geng, J. Yang, Y. Qi et al., " $\mathrm{H}_{2} \mathrm{~S}$ generated by heart in rat and its effects on cardiac function," Biochemical and Biophysical Research Communications, vol. 313, no. 2, pp. 362-368, 2004.
[16] W. Zhao, J. Zhang, Y. Lu, and R. Wang, “The vasorelaxant effect of $\mathrm{H}_{2} \mathrm{~S}$ as a novel endogenous gaseous $\mathrm{K}_{\mathrm{ATP}}$ channel opener," The EMBO Journal, vol. 20, no. 21, pp. 6008-6016, 2001.

[17] G. Yang, L. Wu, B. Jiang et al., " $\mathrm{H}_{2} \mathrm{~S}$ as a physiologic vasorelaxant: hypertension in mice with deletion of cystathionine gamma-lyase," Science, vol. 322, no. 5901, pp. 587-590, 2008.

[18] J. Bełtowski and A. Jamroz-Wiśniewska, "Hydrogen sulfide and endothelium-dependent vasorelaxation," Molecules, vol. 19, no. 12, pp. 21183-21199, 2014.

[19] M. Ishigami, K. Hiraki, K. Umemura, Y. Ogasawara, K. Ishii, and H. Kimura, "A source of hydrogen sulfide and a mechanism of its release in the brain," Antioxidants and Redox Signaling, vol. 11, no. 2, pp. 205-214, 2009.

[20] K. R. Olson, N. L. Whitfield, S. E. Bearden et al., "Hypoxic pulmonary vasodilation: a paradigm shift with a hydrogen sulfide mechanism," The American Journal of PhysiologyRegulatory Integrative and Comparative Physiology, vol. 298, no. 1, pp. R51-R60, 2010.

[21] O. Kabil and R. Banerjee, "Enzymology of $\mathrm{H}_{2} \mathrm{~S}$ biogenesis, decay and signaling," Antioxidants and Redox Signaling, vol. 20, no. 5, pp. 770-782, 2014.

[22] H. Kimura, "Hydrogen sulfide: its production, release and functions," Amino Acids, vol. 41, no. 1, pp. 113-121, 2011.

[23] Y. Kimura, Y.-I. Goto, and H. Kimura, "Hydrogen sulfide increases glutathione production and suppresses oxidative stress in mitochondria," Antioxidants \& Redox Signaling, vol. 12, no. 1, pp. 1-13, 2010.

[24] N. Shibuya, S. Koike, M. Tanaka et al., "A novel pathway for the production of hydrogen sulfide from $\mathrm{D}$-cysteine in mammalian cells," Nature Communications, vol. 4, article 1366, 2013.

[25] H. Kimura, "Metabolic turnover of hydrogen sulfide," Frontiers in Physiology, vol. 3, article 101, 2012.

[26] W. K. Alderton, C. E. Cooper, and R. G. Knowles, "Nitric oxide synthases: structure, function and inhibition," Biochemical Journal, vol. 357, no. 3, pp. 593-615, 2001.

[27] H. M. Abu-Soud and D. J. Stuehr, "Nitric oxide synthases reveal a role for calmodulin in controlling electron transfer," Proceedings of the National Academy of Sciences of the United States of America, vol. 90, no. 22, pp. 10769-10772, 1993.

[28] D. Stuehr, S. Pou, and G. M. Rosen, "Oxygen reduction by nitricoxide synthases," The Journal of Biological Chemistry, vol. 276, no. 18, pp. 14533-14536, 2001.

[29] R. G. Knowles, M. Palacios, R. M. J. Palmer, and S. Moncada, "Formation of nitric oxide from L-arginine in the central nervous system: a transduction mechanism for stimulation of the soluble guanylate cyclase," Proceedings of the National Academy of Sciences of the United States of America, vol. 86, no. 13, pp. 5159-5162, 1989.

[30] U. Förstermann, E. I. Closs, J. S. Pollock et al., "Nitric oxide synthase isozymes: characterization, purification, molecular cloning, and functions," Hypertension, vol. 23, no. 6, part 2, pp. 1121-1131, 1994.

[31] M. A. Marletta, P. S. Yoon, R. Iyengar, C. D. Leaf, and J. S. Wishnok, "Macrophage oxidation of L-arginine to nitrite and nitrate: nitric oxide is an intermediate," Biochemistry, vol. 27, no. 24, pp. 8706-8711, 1988.

[32] Y. Yui, R. Hattori, K. Kosuga et al., "Calmodulin-independent nitric oxide synthase from rat polymorphonuclear neutrophils," The Journal of Biological Chemistry, vol. 266, no. 6, pp. 33693371, 1991. 
[33] P. A. Marsden A, H. H. Q. Heng, S. W. Scherer et al., "Structure and chromosomal localization of the human constitutive endothelial nitric oxide synthase gene," The Journal of Biological Chemistry, vol. 268, no. 23, pp. 17478-17488, 1993.

[34] N. S. Bryan, K. Bian, and F. Murad, "Discovery of the nitric oxide signaling pathway and targets for drug development," Frontiers in Bioscience, vol. 14, no. 1, pp. 1-18, 2009.

[35] J. O. Lundberg, E. Weitzberg, and M. T. Gladwin, "The nitratenitrite-nitric oxide pathway in physiology and therapeutics," Nature Reviews Drug Discovery, vol. 7, no. 2, pp. 156-167, 2008.

[36] J. O. Lundberg and E. Weitzberg, "NO-synthase independent NO generation in mammals," Biochemical and Biophysical Research Communications, vol. 396, no. 1, pp. 39-45, 2010.

[37] F. X. Guix, I. Uribesalgo, M. Coma, and F. J. Muñoz, "The physiology and pathophysiology of nitric oxide in the brain," Progress in Neurobiology, vol. 76, no. 2, pp. 126-152, 2005.

[38] Y. Hou, Z. Guo, J. Li, and P. G. Wang, "Seleno compounds and glutathione peroxidase catalyzed decomposition of Snitrosothiols," Biochemical and Biophysical Research Communications, vol. 228, no. 1, pp. 88-93, 1996.

[39] D. Nikitovic and A. Holmgren, "S-nitrosoglutathione is cleaved by the thioredoxin system with liberation of glutathione and redox regulating nitric oxide," The Journal of Biological Chemistry, vol. 271, no. 32, pp. 19180-19185, 1996.

[40] C. Seregélyes, A. U. Igamberdiev, A. Maassen, J. Hennig, D. Dudits, and R. D. Hill, "NO-degradation by alfalfa class 1 hemoglobin (Mhb1): a possible link to PR-la gene expression in Mhb1-overproducing tobacco plants," FEBS Letters, vol. 571, no. 1-3, pp. 61-66, 2004.

[41] M. Whiteman, U. Ketsawatsakul, and B. Halliwell, "A reassessment of the peroxynitrite scavenging activity of uric acid," Annals of the New York Academy of Sciences, vol. 962, pp. 242259, 2002.

[42] K. R. Olson, "A practical look at the chemistry and biology of hydrogen sulfide," Antioxidants and Redox Signaling, vol. 17, no. 1, pp. 32-44, 2012.

[43] J. M. Fukuto, S. J. Carrington, D. J. Tantillo et al., "Small molecule signaling agents: the integrated chemistry and biochemistry of nitrogen oxides, oxides of carbon, dioxygen, hydrogen sulfide, and their derived species," Chemical Research in Toxicology, vol. 25, no. 4, pp. 769-793, 2012.

[44] H. Kimura, "Production and physiological effects of hydrogen sulfide," Antioxidants \& Redox Signaling, vol. 20, no. 5, pp. 783793, 2014.

[45] A. Fago, F. B. Jensen, B. Tota et al., "Integrating nitric oxide, nitrite and hydrogen sulfide signaling in the physiological adaptations to hypoxia: a comparative approach," Comparative Biochemistry and Physiology Part A: Molecular \& Integrative Physiology, vol. 162, no. 1, pp. 1-6, 2012.

[46] M. Whiteman, J. S. Armstrong, S. H. Chu et al., "The novel neuromodulator hydrogen sulfide: an endogenous peroxynitrite 'scavenger'?" Journal of Neurochemistry, vol. 90, no. 3, pp. 765-768, 2004.

[47] S. Bruce King, "Potential biological chemistry of hydrogen sulfide $\left(\mathrm{H}_{2} \mathrm{~S}\right)$ with the nitrogen oxides," Free Radical Biology and Medicine, vol. 55, pp. 1-7, 2013.

[48] J. M. Fukuto, M. I. Jackson, N. Kaludercic, and N. Paolocci, "Examining nitroxyl in biological systems," Methods in Enzymology, vol. 440, pp. 411-431, 2008.

[49] Q.-C. Yong, L.-F. Hu, S. Wang, D. Huang, and J.-S. Bian, "Hydrogen sulfide interacts with nitric oxide in the heart: possible involvement of nitroxyl," Cardiovascular Research, vol. 88, no. 3, pp. 482-491, 2010.

[50] Y. Ge and R. L. Moss, "Nitroxyl, redox switches, cardiac myofilaments, and heart failure: a prequel to novel therapeutics?" Circulation Research, vol. 111, no. 8, pp. 954-956, 2012.

[51] A. V. Zima and L. A. Blatter, "Redox regulation of cardiac calcium channels and transporters," Cardiovascular Research, vol. 71, no. 2, pp. 310-321, 2006.

[52] G. Keceli, C. D. Moore, J. W. Labonte, and J. P. Toscano, "NMR detection and study of hydrolysis of HNO-derived sulfinamides," Biochemistry, vol. 52, no. 42, pp. 7387-7396, 2013.

[53] M. R. Kumars, J. M. Fukuto, K. M. Miranda, and P. J. Farmer, "Reactions of HNO with heme proteins: new routes to HNOheme complexes and insight into physiological effects," Inorganic Chemistry, vol. 49, no. 14, pp. 6283-6292, 2010.

[54] A. Arcaro, G. Lembo, and C. G. Tocchetti, "Nitroxyl (HNO) for treatment of acute heart failure," Current Heart Failure Reports, vol. 11, no. 3, pp. 227-235, 2014.

[55] G. Kojda and K. Kottenberg, "Regulation of basal myocardial function by NO," Cardiovascular Research, vol. 41, no. 3, pp. 514523, 1999.

[56] M. G. Vila-Petroff, A. Younes, J. Egan, E. G. Lakatta, and S. J. Sollott, "Activation of distinct cAMP-dependent and cGMPdependent pathways by nitric oxide in cardiac myocytes," Circulation Research, vol. 84, no. 9, pp. 1020-1031, 1999.

[57] S. O. Marx, S. Reiken, Y. Hisamatsu et al., "PKA phosphorylation dissociates FKBP12.6 from the calcium release channel (ryanodine receptor): defective regulation in failing hearts," Cell, vol. 101, no. 4, pp. 365-376, 2000.

[58] A. M. Shah, H. A. Spurgeon, S. J. Sollott, A. Talo, and E. G. Lakatta, "8-Bromo-cGMP reduces the myofilament response to $\mathrm{Ca}^{2+}$ in intact cardiac myocytes," Circulation Research, vol. 74, no. 5, pp. 970-978, 1994.

[59] E. Takimoto, H. C. Champion, D. Belardi et al., "cGMP catabolism by phosphodiesterase $5 \mathrm{~A}$ regulates cardiac adrenergic stimulation by NOS3-dependent mechanism," Circulation Research, vol. 96, no. 1, pp. 100-109, 2005.

[60] L. Xu, J. P. Eu, G. Meissner, and J. S. Stamler, "Activation of the cardiac calcium release channel (Ryanodoine receptor) by polyS-nitrosylation," Science, vol. 279, no. 5348, pp. 234-237, 1998.

[61] B. Geng, L. Chang, C. Pan et al., "Endogenous hydrogen sulfide regulation of myocardial injury induced by isoproterenol," Biochemical and Biophysical Research Communications, vol. 318, no. 3, pp. 756-763, 2004.

[62] Y.-G. Sun, Y.-X. Cao, W.-W. Wang, S.-F. Ma, T. Yao, and Y.C. Zhu, "Hydrogen sulphide is an inhibitor of L-type calcium channels and mechanical contraction in rat cardiomyocytes," Cardiovascular Research, vol. 79, no. 4, pp. 632-641, 2008.

[63] Q. C. Yong, T.-T. Pan, L.-F. Hu, and J.-S. Bian, "Negative regulation of beta-adrenergic function by hydrogen sulphide in the rat hearts," Journal of Molecular and Cellular Cardiology, vol. 44, no. 4, pp. 701-710, 2008.

[64] Y.-H. Liu, M. Lu, L.-F. Hu, P. T.-H. Wong, G. D. Webb, and J.S. Bian, "Hydrogen sulfide in the mammalian cardiovascular system," Antioxidants and Redox Signaling, vol. 17, no. 1, pp. 141185, 2012.

[65] M. W. Warenycia, J. A. Steele, E. Karpinski, and R. J. Reiffenstein, "Hydrogen sulfide in combination with taurine or cysteic acid reversibly abolishes sodium currents in neuroblastoma cells," NeuroToxicology, vol. 10, no. 2, pp. 191-199, 1989. 
[66] C. Szabõ, "Hydrogen sulphide and its therapeutic potential," Nature Reviews Drug Discovery, vol. 6, no. 11, pp. 917-935, 2007.

[67] J. L. Miljkovic, I. Kenkel, I. Ivanović-Burmazović, and M. R. Filipovic, "Generation of HNO and HSNO from nitrite by heme-iron-catalyzed metabolism with $\mathrm{H}_{2} \mathrm{~S}$," Angewandte Chemie, vol. 52, no. 46, pp. 12061-12064, 2013.

[68] S. L. Quiroga, A. E. Almaraz, V. T. Amorebieta, L. L. Perissinotti, and J. A. Olabe, "Addition and redox reactivity of hydrogen sulfides $\left(\mathrm{H}_{2} \mathrm{~S} / \mathrm{HS}^{-}\right)$with nitroprusside: new chemistry of nitrososulfide ligands," Chemistry, vol. 17, no. 15, pp. 4145-4156, 2011.

[69] M. R. Filipovic and I. Ivanovic-Burmazovic, "The kinetics and character of the intermediates formed in the reaction between sodium nitroprusside and hydrogen sulfide need further clarification," Chemistry - A European Journal, vol. 18, no. 42, pp. 13538-13540, 2012.

[70] N. Paolocci, T. Katori, H. C. Champion et al., "Positive inotropic and lusitropic effects of HNO/NO- in failing hearts: Independence from $\beta$-adrenergic signaling," Proceedings of the National Academy of Sciences of the United States of America, vol. 100, no. 9, pp. 5537-5542, 2003.

[71] N. Paolocci, W. F. Saavedra, K. M. Miranda et al., "Nitroxyl anion exerts redox-sensitive positive cardiac inotropy in vivo by calcitonin gene-related peptide signaling," Proceedings of the National Academy of Sciences of the United States of America, vol. 98, no. 18, pp. 10463-10468, 2001.

[72] C. G. Tocchetti, W. Wang, J. P. Froehlich et al., "Nitroxyl improves cellular heart function by directly enhancing cardiac sarcoplasmic reticulum $\mathrm{Ca}^{2+}$ cycling," Circulation Research, vol. 100, no. 1, pp. 96-104, 2007.

[73] V. Sivakumaran, B. A. Stanley, C. G. Tocchetti et al., "HNO Enhances SERCA2a activity and cardiomyocyte function by promoting redox-dependent phospholamban oligomerization," Antioxidants and Redox Signaling, vol. 19, no. 11, pp. 1185-1197, 2013.

[74] T. Katori, D. B. Hoover, J. L. Ardell et al., "Calcitonin generelated peptide in vivo positive inotropy is attributable to regional sympatho-stimulation and is blunted in congestive heart failure," Circulation Research, vol. 96, no. 2, pp. 234-243, 2005.

[75] C. G. Tocchetti, B. A. Stanley, C. I. Murray et al., "Playing with cardiac 'redox switches': the 'HNO way' to modulate cardiac function," Antioxidants \& Redox Signaling, vol. 14, no. 9, pp. 1687-1698, 2011.

[76] J. K. Wachira and T. P. Stys, "Cardiovascular disease and bridging the diagnostic gap," South Dakota Medicine, vol. 66, no. 9, pp. 366-369, 2013.

[77] S. P. Jones, W. G. Girod, A. J. Palazzo et al., "Myocardial ischemia-reperfusion injury is exacerbated in absence of endothelial cell nitric oxide synthase," The American Journal of Physiology-Heart and Circulatory Physiology, vol. 276, no. 5, pp. H1567-H1573, 1999.

[78] S. P. Jones, J. J. M. Greer, R. Van Haperen, D. J. Duncker, R. De Crom, and D. J. Lefer, "Endothelial nitric oxide synthase overexpression attenuates congestive heart failure in mice," Proceedings of the National Academy of Sciences of the United States of America, vol. 100, no. 8, pp. 4891-4896, 2003.

[79] S. Janssens, P. Pokreisz, L. Schoonjans et al., "Cardiomyocytespecific overexpression of nitric oxide synthase 3 improves left ventricular performance and reduces compensatory hypertrophy after myocardial infarction," Circulation Research, vol. 94, no. 9, pp. 1256-1262, 2004.
[80] B. W. Roberts, J. Mitchell, J. H. Kilgannon, M. E. Chansky, and S. Trzeciak, "Nitric oxide donor agents for the treatment of ischemia/reperfusion injury in human subjects: a systematic review," Shock, vol. 39, no. 3, pp. 229-239, 2013.

[81] T. Mizuno, M. Watanabe, T. Sakamoto, and M. Sunamori, "L-arginine, a nitric oxide precursor, attenuates ischemiareperfusion injury by inhibiting inositol-1,4,5-triphosphate," Journal of Thoracic and Cardiovascular Surgery, vol. 115, no. 4, pp. 931-936, 1998.

[82] A. Beresewicz, E. Karwatowska-Prokopczuk, B. Lewartowski, and K. Cedro-Ceremuzynska, "A protective role of nitric oxide in isolated ischaemic/reperfused rat heart," Cardiovascular Research, vol. 30, no. 6, pp. 1001-1008, 1995.

[83] R. Schulz, M. Kelm, and G. Heusch, "Nitric oxide in myocardial ischemia/reperfusion injury," Cardiovascular Research, vol. 61, no. 3, pp. 402-413, 2004.

[84] Z. Xu, X. Ji, and P. G. Boysen, "Exogenous nitric oxide generates ROS and induces cardioprotection: Involvement of PKG, mitochondrial KATP channels, and ERK," The American Journal of Physiology-Heart and Circulatory Physiology, vol. 286, no. 4, pp. H1433-H1440, 2004.

[85] D.-M. Zhang, Y. Chai, J. R. Erickson, J. H. Brown, D. M. Bers, and Y.-F. Lin, "Modulation of sarcolemmal ATP-sensitive potassium channels by nitric oxide via sGC/PKG/ROS/ERK1/2/ CaMKII signaling in ventricular cardiomyocytes," The Journal of Physiology, vol. 592, part 5, pp. 971-990, 2014.

[86] A. Calderone, C. M. Thaik, N. Takahashi, D. L. F. Chang, and W. S. Colucci, "Nitric oxide, atrial natriuretic peptide, and cyclic GMP inhibit the growth-promoting effects of norepinephrine in cardiac myocytes and fibroblasts," Journal of Clinical Investigation, vol. 101, no. 4, pp. 812-818, 1998.

[87] Y. Z. Zhu, Z. Wang, P. Ho et al., "Hydrogen sulfide and its possible roles in myocardial ischemia in experimental rats," Journal of Applied Physiology, vol. 102, no. 1, pp. 261-268, 1985.

[88] Z. Zhang, H. Huang, P. Liu, C. Tang, and J. Wang, "Hydrogen sulfide contributes to cardioprotection during ischemiareperfusion injury by opening KATP channels," Canadian Journal of Physiology and Pharmacology, vol. 85, no. 12, pp. 1248-1253, 2007.

[89] R. M. Osipov, M. P. Robich, J. Feng et al., "Effect of hydrogen sulfide in a porcine model of myocardial ischemia-reperfusion: comparison of different administration regimens and characterization of the cellular mechanisms of protection," Journal of Cardiovascular Pharmacology, vol. 54, no. 4, pp. 287-297, 2009.

[90] X. Wang, Q. Wang, W. Guo, and Y. Z. Zhu, "Hydrogen sulfide attenuates cardiac dysfunction in a rat model of heart failure: a mechanism through cardiac mitochondrial protection," Bioscience Reports, vol. 31, no. 2, pp. 87-98, 2011.

[91] S. Jha, J. W. Calvert, M. R. Duranski, A. Ramachandran, and D. J. Lefer, "Hydrogen sulfide attenuates hepatic ischemiareperfusion injury: Role of antioxidant and antiapoptotic signaling," The American Journal of Physiology-Heart and Circulatory Physiology, vol. 295, no. 2, pp. H801-H806, 2008.

[92] C. E. Cooper and G. C. Brown, "The inhibition of mitochondrial cytochrome oxidase by the gases carbon monoxide, nitric oxide, hydrogen cyanide and hydrogen sulfide: chemical mechanism and physiological significance," Journal of Bioenergetics and Biomembranes, vol. 40, no. 5, pp. 533-539, 2008.

[93] Q. C. Yong, S. W. Lee, C. S. Foo, K. L. Neo, X. Chen, and J.-S. Bian, "Endogenous hydrogen sulphide mediates the cardioprotection induced by ischemic postconditioning," The American 
Journal of Physiology-Heart and Circulatory Physiology, vol. 295, no. 3, pp. H1330-H1340, 2008.

[94] J.-S. Bian, C. Y. Qian, T.-T. Pan et al., "Role of hydrogen sulfide in the cardioprotection caused by ischemic preconditioning in the rat heart and cardiac myocytes," Journal of Pharmacology and Experimental Therapeutics, vol. 316, no. 2, pp. 670-678, 2006.

[95] T.-T. Pan, Y. Q. Chen, and J.-S. Bian, "All in the timing: a comparison between the cardioprotection induced by $\mathrm{H}_{2} \mathrm{~S}$ preconditioning and post-infarction treatment," European Journal of Pharmacology, vol. 616, no. 1-3, pp. 160-165, 2009.

[96] T.-T. Pan, K. L. Neo, L.-F. Hu, Q. C. Yong, and J.-S. Bian, “ $\mathrm{H}_{2} \mathrm{~S}$ preconditioning-induced $\mathrm{PKC}$ activation regulates intracellular calcium handling in rat cardiomyocytes," The American Journal of Physiology-Cell Physiology, vol. 294, no. 1, pp. C169-C177, 2008.

[97] T.-T. Pan, Z.-N. Feng, S. W. Lee, P. K. Moore, and J.-S. Bian, "Endogenous hydrogen sulfide contributes to the cardioprotection by metabolic inhibition preconditioning in the rat ventricular myocytes," Journal of Molecular and Cellular Cardiology, vol. 40, no. 1, pp. 119-130, 2006.

[98] B. Sojitra, Y. Bulani, U. K. Putcha et al., "Nitric oxide synthase inhibition abrogates hydrogen sulfide-induced cardioprotection in mice," Molecular and Cellular Biochemistry, vol. 360, no. 1-2, pp. 61-69, 2012.

[99] Z. Altaany, G. Yang, and R. Wang, "Crosstalk between hydrogen sulfide and nitric oxide in endothelial cells," Journal of Cellular and Molecular Medicine, vol. 17, no. 7, pp. 879-888, 2013.

[100] A. L. King, D. J. Polhemus, S. Bhushan et al., "Hydrogen sulfide cytoprotective signaling is endothelial nitric oxide synthasenitric oxide dependent," Proceedings of the National Academy of Sciences of the United States of America, vol. 111, no. 8, pp. 31823187, 2014.

[101] S. Kubo, I. Doe, Y. Kurokawa, H. Nishikawa, and A. Kawabata, "Direct inhibition of endothelial nitric oxide synthase by hydrogen sulfide: contribution to dual modulation of vascular tension," Toxicology, vol. 232, no. 1-2, pp. 138-146, 2007.

[102] B. Geng, Y. Cui, J. Zhao et al., "Hydrogen sulfide downregulates the aortic L-arginine/nitric oxide pathway in rats," The American Journal of Physiology-Regulatory Integrative and Comparative Physiology, vol. 293, no. 4, pp. R1608-R1618, 2007.

[103] G. Szalay, M. Sauter, J. Hald, A. Weinzierl, R. Kandolf, and K. Klingel, "Sustained nitric oxide synthesis contributes to immunopathology in ongoing myocarditis attributable to interleukin-10 disorders," The American Journal of Pathology, vol. 169, no. 6, pp. 2085-2093, 2006.

[104] P. Mukhopadhyay, M. Rajesh, S. Bátkai et al., "Role of superoxide, nitric oxide, and peroxynitrite in doxorubicin-induced cell death in vivo and in vitro," The American Journal of PhysiologyHeart and Circulatory Physiology, vol. 296, no. 5, pp. H1466H1483, 2009.

[105] W. Hua, Q. Chen, F. Gong, C. Xie, S. Zhou, and L. Gao, "Cardioprotection of $\mathrm{H} 2 \mathrm{~S}$ by downregulating iNOS and upregulating HO-1 expression in mice with CVB3-induced myocarditis," Life Sciences, vol. 93, no. 24, pp. 949-954, 2013.

[106] W. Zhao, J. F. Ndisang, and R. Wang, "Modulation of endogenous production of $\mathrm{H}_{2} \mathrm{~S}$ in rat tissues," Canadian Journal of Physiology and Pharmacology, vol. 81, no. 9, pp. 848-853, 2003.

[107] K. M. Miranda, T. Katori, C. L. Torres De Holding et al., "Comparison of the $\mathrm{NO}$ and $\mathrm{HNO}$ donating properties of diazeniumdiolates: primary amine adducts release $\mathrm{HNO}$ in vivo," Journal of Medicinal Chemistry, vol. 48, no. 26, pp. 82208228, 2005.
[108] B. B. Queliconi, A. P. Wojtovich, S. M. Nadtochiy, A. J. Kowaltowski, and P. S. Brookes, "Redox regulation of the mitochondrial KATP channel in cardioprotection," Biochimica et Biophysica Acta - Molecular Cell Research, vol. 1813, no. 7, pp. 1309-1315, 2011.

[109] B. E. Vanuffelen, J. van der Zee, B. M. de Koster, J. Vansteveninck, and J. G. R. Elferink, "Intracellular but not extracellular conversion of nitroxyl anion into nitric oxide leads to stimulation of human neutrophil migration," Biochemical Journal, vol. 330, part 2, pp. 719-722, 1998.

[110] H. Hayakawa, Y. Hirata, M. Kakoki et al., "Role of nitric oxidecGMP pathway in adrenomedullin-induced vasodilation in the rat," Hypertension, vol. 33, no. 2, pp. 689-693, 1999.

[111] D. K. Mistry and C. J. Garland, "Nitric oxide (NO)-induced activation of large conductance $\mathrm{Ca}^{2+}$-dependent $\mathrm{K}^{+}$channels $\left(\mathrm{BK}_{\mathrm{Ca}}\right)$ in smooth muscle cells isolated from the rat mesenteric artery," British Journal of Pharmacology, vol. 124, no. 6, pp. 11311140, 1998.

[112] M. Alonso-Galicia, A. G. Hudetz, H. Shen, D. R. Harder, and R. J. Roman, "Contribution of 20-HETE to vasodilator actions of nitric oxide in the cerebral microcirculation," Stroke, vol. 30, no. 12, pp. 2727-2734, 1999.

[113] B. P. Luchsinger, E. N. Rich, A. J. Gow, E. M. Williams, J. S. Stamler, and D. J. Singel, "Routes to S-nitroso-hemoglobin formation with heme redox and preferential reactivity in the $\beta$ subunits," Proceedings of the National Academy of Sciences of the United States of America, vol. 100, no. 2, pp. 461-466, 2003.

[114] B. W. Allen, J. S. Stamler, and C. A. Piantadosi, "Hemoglobin, nitric oxide and molecular mechanisms of hypoxic vasodilation," Trends in Molecular Medicine, vol. 15, no. 10, pp. 452-460, 2009.

[115] R. Wang, "Physiological implications of hydrogen sulfide: a whiff exploration that blossomed," Physiological Reviews, vol. 92, no. 2, pp. 791-896, 2012.

[116] W. Zhao and R. Wang, " $\mathrm{H}_{2} \mathrm{~S}$-induced vasorelaxation and underlying cellular and molecular mechanisms," The American Journal of Physiology-Heart and Circulatory Physiology, vol. 283, no. 2, pp. H474-H480, 2002.

[117] S. W. Lee, Y. Cheng, P. Moore, and J. S. Bian, "Hydrogen sulphide regulates intracellular $\mathrm{pH}$ in vascular smooth muscle cells," Biochemical and Biophysical Research Communications, vol. 358, no. 4, pp. 1142-1147, 2007.

[118] L. Kiss, E. A. Deitch, and C. Szabó, "Hydrogen sulfide decreases adenosine triphosphate levels in aortic rings and leads to vasorelaxation via metabolic inhibition," Life Sciences, vol. 83, no. 17-18, pp. 589-594, 2008.

[119] M. Y. Ali, C. Y. Ping, Y.-Y. P. Mok et al., "Regulation of vascular nitric oxide in vitro and in vivo; a new role for endogenous hydrogen sulphide?" British Journal of Pharmacology, vol. 149, no. 6, pp. 625-634, 2006.

[120] R. Hosoki, N. Matsuki, and H. Kimura, "The possible role of hydrogen sulfide as an endogenous smooth muscle relaxant in synergy with nitric oxide," Biochemical and Biophysical Research Communications, vol. 237, no. 3, pp. 527-531, 1997.

[121] Y.-H. Liu and J.-S. Bian, "Bicarbonate-dependent effect of hydrogen sulfide on vascular contractility in rat aortic rings," American Journal of Physiology: Cell Physiology, vol. 299, no. 4, pp. C866-C872, 2010.

[122] K.-T. Huang, C.-C. Yin, J.-H. Wu, and H.-H. Huang, "Superoxide determines nitric oxide uptake rate by vascular smooth muscle cells," FEBS Letters, vol. 579, no. 20, pp. 4349-4354, 2005. 
[123] A. Berenyiova, M. Grman, A. Mijuskovic et al., "The reaction products of sulfide and S-nitrosoglutathione are potent vasorelaxants," Nitric Oxide, vol. 46, pp. 123-130, 2015.

[124] K. L. Andrews, J. C. Irvine, M. Tare et al., "A role for nitroxyl (HNO) as an endothelium-derived relaxing and hyperpolarizing factor in resistance arteries," British Journal of Pharmacology, vol. 157, no. 4, pp. 540-550, 2009.

[125] K. M. Rusche, M. M. Spiering, and M. A. Marletta, "Reactions catalyzed by tetrahydrobiopterin-free nitric oxide synthase," Biochemistry, vol. 37, no. 44, pp. 15503-15512, 1998.

[126] S. Adak, Q. Wang, and D. J. Stuehr, "Arginine conversion to nitroxide by tetrahydrobiopterin-free neuronal nitric-oxide synthase: implications for mechanism," Journal of Biological Chemistry, vol. 275, no. 43, pp. 33554-33561, 2000.

[127] J. C. Wanstall, T. K. Jeffery, A. Gambino, F. Lovren, and C. R. Triggle, "Vascular smooth muscle relaxation mediated by nitric oxide donors: a comparison with acetylcholine, nitric oxide and nitroxyl ion," British Journal of Pharmacology, vol. 134, no. 3, pp. 463-472, 2001.

[128] J. C. Irvine, J. L. Favaloro, and B. K. Kemp-Harper, "NOactivates soluble guanylate cyclase and $\mathrm{Kv}$ channels to vasodilate resistance arteries," Hypertension, vol. 41, no. 6, pp. 1301-1307, 2003.

[129] K. L. Andrews, N. G. Lumsden, J. Farry et al., "Nitroxyl: a vasodilator of human vessels that is not susceptible to tolerance," Clinical Science (London), vol. 129, no. 2, pp. 179-187, 2015.

[130] M. Dux, C. Will, B. Vogler, M. R. Filipovic, and K. Messlinger, "Meningeal blood flow is controlled by $\mathrm{H}_{2} \mathrm{~S}-\mathrm{NO}$ crosstalk activating HNO-TRPA1-CGRP signalling," British Journal of Pharmacology, 2015.

[131] W. Yanfei, S. Lin, D. Junbao, and T. Chaoshu, "Impact of 1arginine on hydrogen sulfide/cystathionine- $\gamma$-lyase pathway in rats with high blood flow-induced pulmonary hypertension," Biochemical and Biophysical Research Communications, vol. 345, no. 2, pp. 851-857, 2006.

[132] C. Coletta, A. Papapetropoulos, K. Erdelyi et al., "Hydrogen sulfide and nitric oxide are mutually dependent in the regulation of angiogenesis and endothelium-dependent vasorelaxation," Proceedings of the National Academy of Sciences of the United States of America, vol. 109, no. 23, pp. 9161-9166, 2012.

[133] M. Eberhardt, M. Dux, B. Namer et al., " $\mathrm{H}_{2} \mathrm{~S}$ and NO cooperatively regulate vascular tone by activating a neuroendocrine HNO-TRPA1-CGRP signalling pathway," Nature Communications, vol. 5, article 4381, 2014.

[134] Q. Huang, A. Sparatore, P. del Soldato, L. Wu, and K. Desai, "Hydrogen sulfide releasing aspirin, ACS14, attenuates high glucose-induced increased methylglyoxal and oxidative stress in cultured vascular smooth muscle cells," PLoS ONE, vol. 9, no. 6, Article ID e97315, 2014.

[135] L. Munaron, "Intracellular calcium, endothelial cells and angiogenesis," Recent Patents on Anti-Cancer Drug Discovery, vol. 1, no. 1, pp. 105-119, 2006.

[136] C. Fischer, M. Schneider, and P. Carmeliet, "Principles and therapeutic implications of angiogenesis, vasculogenesis and arteriogenesis," Handbook of Experimental Pharmacology, vol. 176, no. 2, pp. 157-212, 2006.

[137] M. Ziche and L. Morbidelli, "Nitric oxide and angiogenesis," Journal of Neuro-Oncology, vol. 50, no. 1-2, pp. 139-148, 2000.

[138] L. Munaron and A. Fiorio Pla, "Endothelial calcium machinery and angiogenesis: understanding physiology to interfere with pathology," Current Medicinal Chemistry, vol. 16, no. 35, pp. 4691-4703, 2009.
[139] W.-J. Cai, M.-J. Wang, P. K. Moore, H.-M. Jin, T. Yao, and Y.C. Zhu, "The novel proangiogenic effect of hydrogen sulfide is dependent on Akt phosphorylation," Cardiovascular Research, vol. 76, no. 1, pp. 29-40, 2007.

[140] A. Papapetropoulos, A. Pyriochou, Z. Altaany et al., "Hydrogen sulfide is an endogenous stimulator of angiogenesis," Proceedings of the National Academy of Sciences of the United States of America, vol. 106, no. 51, pp. 21972-21977, 2009.

[141] M. Bucci, A. Papapetropoulos, V. Vellecco et al., "Hydrogen sulfide is an endogenous inhibitor of phosphodiesterase activity," Arteriosclerosis, Thrombosis, and Vascular Biology, vol. 30, no. 10, pp. 1998-2004, 2010.

[142] S. Dimmeler, I. Fleming, B. Fisslthaler, C. Hermann, R. Busse, and A. M. Zeiher, "Activation of nitric oxide synthase in endothelial cells by Akt-dependent phosphorylation," Nature, vol. 399, no. 6736, pp. 601-605, 1999.

[143] N. D. Tsihlis, J. Murar, M. R. Kapadia et al., "Isopropylamine NONOate (IPA/NO) moderates neointimal hyperplasia following vascular injury," Journal of Vascular Surgery, vol. 51, no. 5, pp. 1248-1259, 2010.

[144] A. J. Norris, M. R. Sartippour, M. Lu et al., "Nitroxyl inhibits breast tumor growth and angiogenesis," International Journal of Cancer, vol. 122, no. 8, pp. 1905-1910, 2008.

[145] M. Matsuda and I. Shimomura, "Increased oxidative stress in obesity: implications for metabolic syndrome, diabetes, hypertension, dyslipidemia, atherosclerosis, and cancer," Obesity Research \& Clinical Practice, vol. 7, no. 5, pp. e330-e341, 2013.

[146] D. G. Harrison and M. C. Gongora, "Oxidative stress and hypertension," Medical Clinics of North America, vol. 93, no. 3, pp. 621-635, 2009.

[147] D.-F. Dai and P. S. Rabinovitch, "Cardiac aging in mice and humans: the role of mitochondrial oxidative stress," Trends in Cardiovascular Medicine, vol. 19, no. 7, pp. 213-220, 2009.

[148] S. Selemidis, G. J. Dusting, H. Peshavariya, B. K. Kemp-Harper, and G. R. Drummond, "Nitric oxide suppresses NADPH oxidase-dependent superoxide production by S-nitrosylation in human endothelial cells," Cardiovascular Research, vol. 75, no. 2, pp. 349-358, 2007.

[149] B. E. Lopez, M. Shinyashiki, T. H. Han, and J. M. Fukuto, "Antioxidant actions of nitroxyl (HNO)," Free Radical Biology and Medicine, vol. 42, no. 4, pp. 482-491, 2007.

[150] R. N. Dixon, "The heats of formation of HNO and of DNO," The Journal of Chemical Physics, vol. 104, no. 17, pp. 6905-6906, 1996.

[151] D. A. Wink, K. M. Miranda, M. G. Espey et al., "Mechanisms of the antioxidant effects of nitric oxide," Antioxidants and Redox Signaling, vol. 3, no. 2, pp. 203-213, 2001.

[152] E. Q. Lin, J. C. Irvine, A. H. Cao et al., "Nitroxyl (HNO) stimulates soluble guanylyl cyclase to suppress cardiomyocyte hypertrophy and superoxide generation," PLOS ONE, vol. 7, no. 4, Article ID e34892, 2012.

[153] A. A. Miller, K. F. Maxwell, S. Chrissobolis et al., "Nitroxyl (HNO) suppresses vascular Nox2 oxidase activity," Free Radical Biology and Medicine, vol. 60, pp. 264-271, 2013.

[154] M. Whiteman, L. Li, I. Kostetski et al., "Evidence for the formation of a novel nitrosothiol from the gaseous mediators nitric oxide and hydrogen sulphide," Biochemical and Biophysical Research Communications, vol. 343, no. 1, pp. 303-310, 2006.

[155] S. A. Suárez, D. E. Bikiel, D. E. Wetzler, M. A. Martí, and F. Doctorovich, "Time-resolved electrochemical quantification of azanone (HNO) at low nanomolar level," Analytical Chemistry, vol. 85, no. 21, pp. 10262-10269, 2013. 
[156] S. Donzelli, M. G. Espey, D. D. Thomas et al., "Discriminating formation of HNO from other reactive nitrogen oxide species," Free Radical Biology and Medicine, vol. 40, no. 6, pp. 1056-1066, 2006.

[157] M. R. Cline, C. Tu, D. N. Silverman, and J. P. Toscano, "Detection of nitroxyl (HNO) by membrane inlet mass spectrometry," Free Radical Biology and Medicine, vol. 50, no. 10, pp. 1274-1279, 2011.

[158] A. T. Wrobel, T. C. Johnstone, A. Deliz Liang, S. J. Lippard, and P. Rivera-Fuentes, "A fast and selective near-infrared fluorescent sensor for multicolor imaging of biological nitroxyl (HNO)," Journal of the American Chemical Society, vol. 136, no. 12, pp. 4697-4705, 2014.

[159] G.-J. Mao, X.-B. Zhang, X.-L. Shi et al., "A highly sensitive and reductant-resistant fluorescent probe for nitroxyl in aqueous solution and serum," Chemical Communications, vol. 50, no. 43, pp. 5790-5792, 2014.

[160] X. Jing, F. Yu, and L. Chen, "Visualization of nitroxyl (HNO) in vivo via a lysosome-targetable near-infrared fluorescent probe," Chemical Communications, vol. 50, no. 91, pp. 14253-14256, 2014.

[161] M. Saleem and H. Ohshima, "Xanthine oxidase converts nitric oxide to nitroxyl that inactivates the enzyme," Biochemical and Biophysical Research Communications, vol. 315, no. 2, pp. 455462, 2004.

[162] P. S. Wong, J. Hyun, J. M. Fukuto et al., "Reaction between S-nitrosothiols and thiols: generation of nitroxyl (HNO) and subsequent chemistry," Biochemistry, vol. 37, no. 16, pp. 53625371, 1998.

[163] N. Paolocci, T. Katori, H. C. Champion et al., "Positive inotropic and lusitropic effects of $\mathrm{HNO} / \mathrm{NO}$ - in failing hearts: independence from $\beta$-adrenergic signaling," Proceedings of the National Academy of Sciences of the United States of America, vol. 100, no. 9, pp. 5537-5542, 2003.

[164] L. T. Cooper Jr., "Myocarditis," The New England Journal of Medicine, vol. 360, no. 15, pp. 1526-1538, 2009.

[165] J. M. Fukuto and S. J. Carrington, "HNO signaling mechanisms," Antioxidants and Redox Signaling, vol. 14, no. 9, pp. 1649-1657, 2011.

[166] H. N. Sabbah, C. G. Tocchetti, M. Wang et al., "Nitroxyl (HNO): a novel approach for the acute treatment of heart failure," Circulation: Heart Failure, vol. 6, no. 6, pp. 1250-1258, 2013.

[167] A. R. Butler and C. Glidewell, "Recent chemical studies of sodium nitroprusside relevant to its hypotensive action," Chemical Society Reviews, vol. 16, pp. 361-380, 1987. 


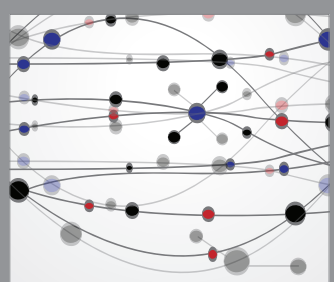

The Scientific World Journal
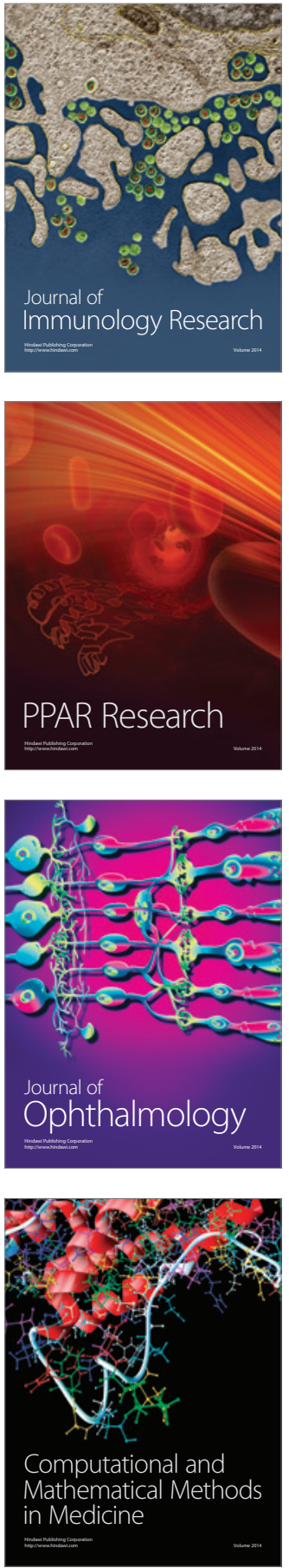

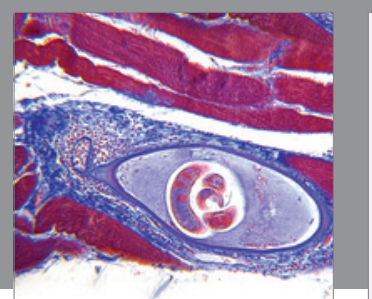

Gastroenterology Research and Practice

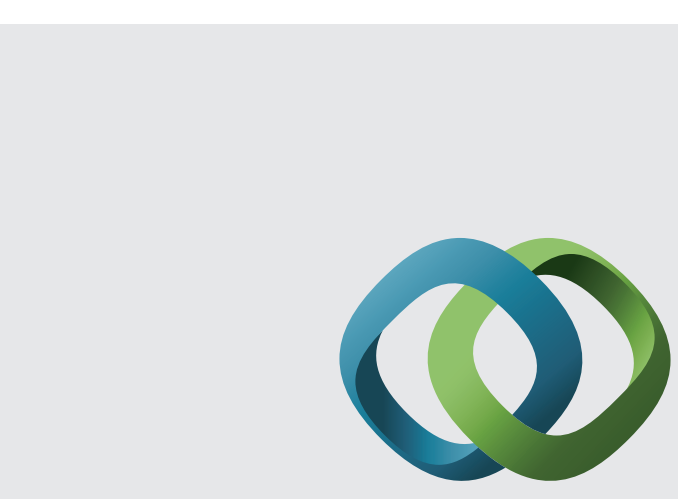

\section{Hindawi}

Submit your manuscripts at

http://www.hindawi.com
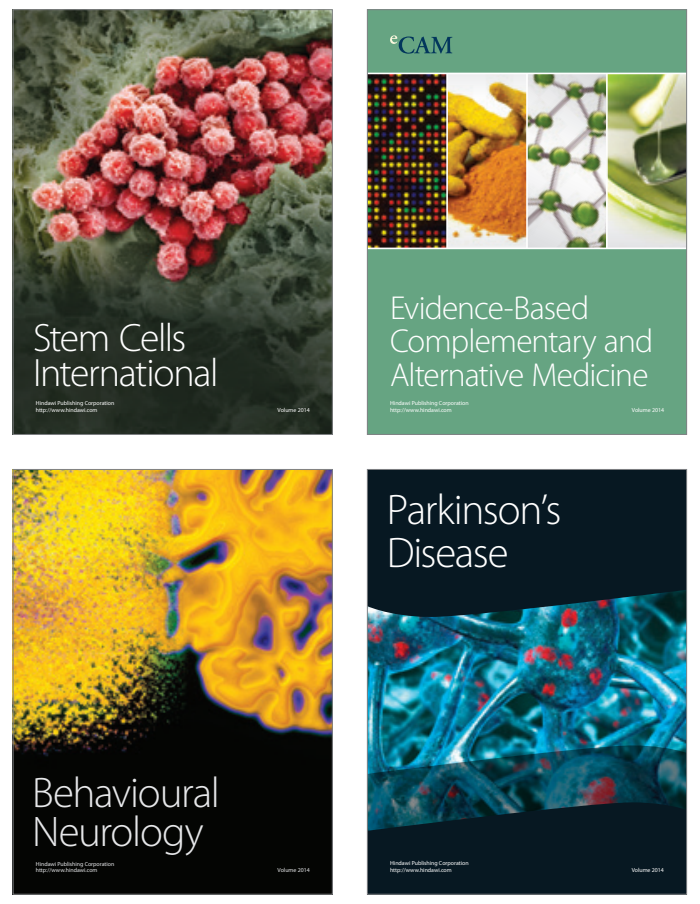
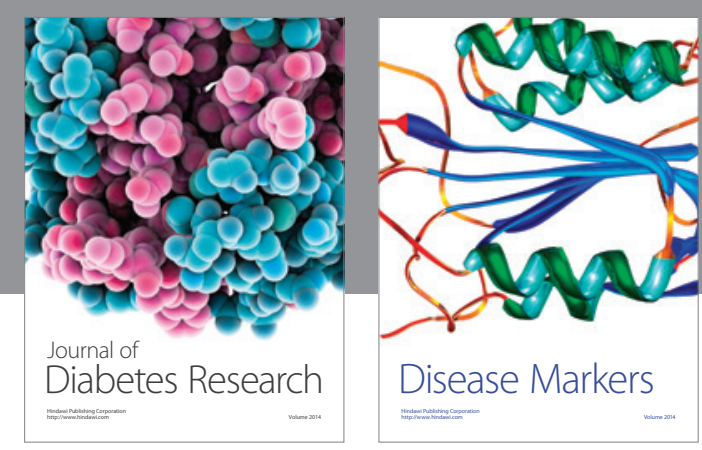

Disease Markers
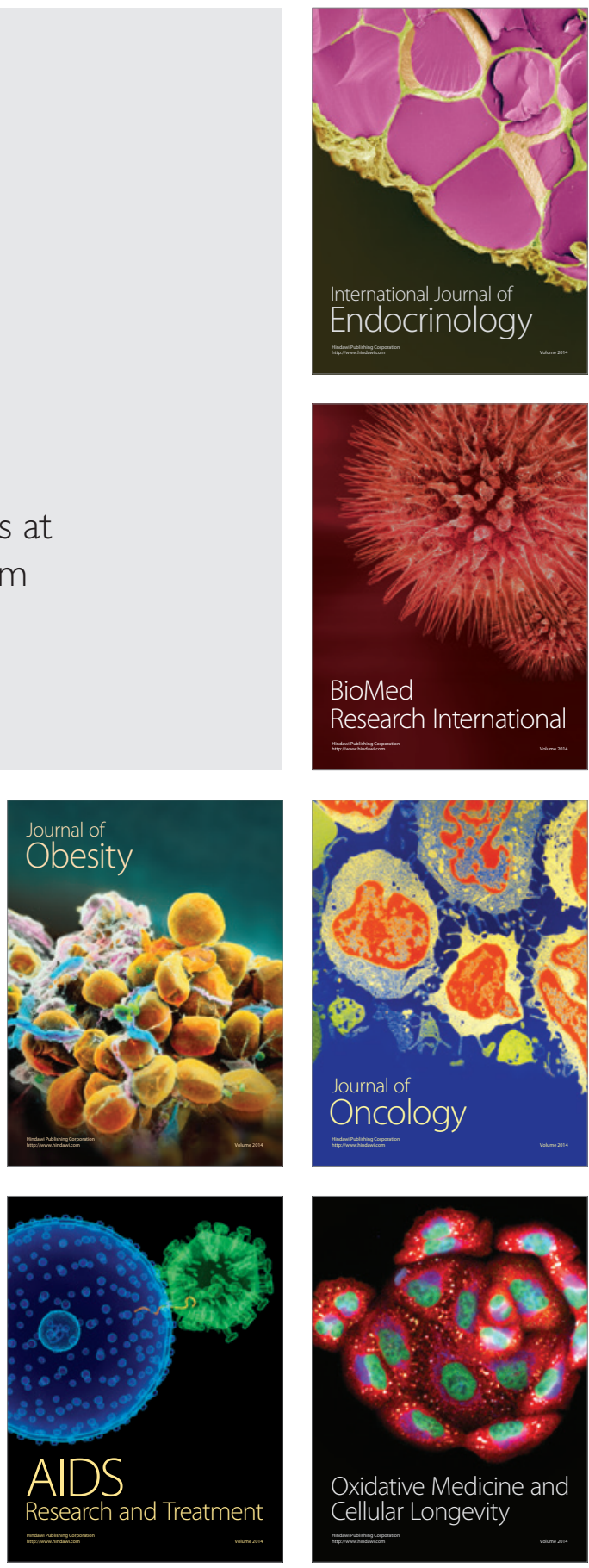